\title{
Bisphosphonates in the management of postmenopausal osteoporosis - optimizing efficacy in clinical practice
}

\author{
Oliver Bock \\ Dieter Felsenberg \\ Center for Muscle and Bone \\ Research, Campus Benjamin Franklin, \\ Charité - University Medicine Berlin, \\ Berlin, Germany
}

\begin{abstract}
Nitrogen-containing bisphosphonates are potent inhibitors of osteoclastic bone resorption. With their individually proven efficacy to significantly reduce the incidence of vertebral and/or non-vertebral fractures and with their overall beneficial safety profile, alendronate, ibandronate, risedronate, and zoledronate are considered today a treatment of first choice in postmenopausal osteoporosis. However, treatment effects in an individual patient and cost-effectiveness in public health perspective are vitally dependent on the long-term patient adherence as well as on compliance and persistence. As compliance and persistence with daily oral bisphosphonates are shown to be suboptimal in many patients, leading to an increased fracture incidence in non-compliant patients, there is a need to improve overall adherence for bisphosphonate treatment in order to achieve maximum treatment effects. One option is to extend dosing intervals to weekly (alendronate, risedronate) or monthly (ibandronate) oral regimens. Less frequent oral regimens are generally preferred by majority of patients. Another alternative is intravenous, instead of oral application (ibandronate, zoledronate). Treatment acceptance could be further improved by IV bisphosphonates with their benefit of only quarterly, or even once-yearly, application. Treatment decisions should be based on anti-fracture efficacy data first. In addition, to ensure best possible patient adherence and maximum treatment benefits, physicians should consider individual patient conditions affecting compliance and persistence as well as patient preferences.
\end{abstract}

Keywords: postmenopausal osteoporosis, bisphosphonates, fracture risk reduction, adherence, dosing frequencies, patient considerations

\section{Introduction}

Osteoporosis is a disease characterized by low bone mass and micro architectural deterioration of bone tissue, leading to enhanced bone fragility and increased susceptibility to fractures (NIH 2001; WHO 2003a). Most common osteoporosis-related, non-trauma-based, fractures affect spine (vertebral bodies), hip, wrist, and humerus, although they can occur at almost any skeletal site.

Osteoporosis is considered a serious public health concern due to its important worldwide prevalence. Currently it is estimated that over 200 million people worldwide suffer from this disease (Cooper 1999). Approximately 30\% of all postmenopausal women have osteoporosis in the United States and in Europe. Available data for the year 2000 point out to 9.0 million osteoporotic fractures, 1.6 million of which were at the hip, 1.7 million at the forearm, and 1.4 million were clinical vertebral fractures. The greatest number of osteoporotic fractures occurred in Europe (34.8\%) (Johnell and Kanis 2006). In Germany in 2003, 7.8 million persons (6.5 million women, 1.3 million men) were affected by osteoporosis and $4.3 \%$ of them experienced at least one clinical fracture. The total direct costs attributable to osteoporosis amounted to $€ 5.4$ billion. Furthermore, the BonEVA Study confirmed that osteoporosis was underdiagnosed, 
undertreated and imposed a considerable economic burden on the health system (Häussler et al 2007).

Aging of populations worldwide will also contribute to a major increase of the incidence of osteoporosis in postmenopausal women (Reginster and Burlet 2006). About 40\%-50\% of women and $13 \%-30 \%$ of men will sustain one or more fragility fractures in their remaining lifetime (Melton et al 1992; Randell et al 1995; Johnell and Kanis 2005; Nguyen et al 2007).

By 2050, the worldwide incidence of hip fracture is expected to increase by $240 \%$ in women and $310 \%$ in men (Gullberg et al 1997). The estimated number of hip fractures worldwide will rise from 1.66 million in 1990 to 6.26 million in 2050 , even though the age-adjusted incidence rates will remain stable (Sambrook and Cooper 2006).

Osteoporosis may result in acute and chronic pain, disabilities, restricted movement until immobilization, impaired quality of life as well as social isolation. It is far more common than other diseases, which commonly capture public attention, eg, the combined lifetime risk of hip, forearm, and vertebral fractures coming to clinical attention is equivalent to the risk posed by cardiovascular diseases (Kanis 2002). In women over 45 years of age, osteoporosis accounts for more days in hospital than may other diseases, including diabetes, myocardial infarction, and breast cancer (Kanis et al 1997).

The total Disability Adjusted Life Years (DALYs) loss was 5.8 million of which $51 \%$ were accounted for by fractures that occurred in Europe and the Americas. Osteoporotic fractures accounted for $0.83 \%$ of the global burden of noncommunicable disease worldwide and for $1.75 \%$ in Europe. Here, osteoporotic fractures accounted for more DALYs loss than common cancers, with the exception of lung cancer (Johnell and Kanis 2006). Although osteoporosis is often associated with increased mortality, it remains under-recognized. Importantly, in 1990, 740,000 deaths worldwide were associated with hip fracture (Johnell and Kanis 2004). Many other studies have shown increase in mortality in connection with osteoporotic fractures (Cooper et al 1993; Center et al 1999; Johnell and Haglund 1999; Cauley et al 2000; Johnell et al 2004). This has been best characterized following hip fracture (Weiss et al 1983; Magaziner et al 1989; Sernbo and Johnell 1993; Todd et al 1995; Browner et al 1996; Melton et al 1998; Forsén et al 1999), but several recent studies of vertebral fracture, eg, Study of Osteoporotic Fractures (SOF) and European Prospective Osteoporosis Study (EPOS), have also indicated higher mortality in affected patients as opposed to the general population (Ismail et al 1998; Kado et al 1999; Ensrud et al 2000; Hasserius et al 2003; Johnell et al 2004).
The objective of treatment in patients with postmenopausal osteoporosis is to reduce the risk of fractures and to prevent the impairment of quality of life as well as to reduce osteoporosis-related mortality. The clinical efficacy of new drugs to treat osteoporosis must be judged in clinical trials that use the reduction of fracture risk as the main end point, rather than trials that use surrogate end points, such as changes in bone mineral density (BMD) (Chapurlat and Delmas 2006).

\section{Management of osteoporosis with nitrogen-containing bisphosphonates}

Nitrogen-containing bisphosphonates are highly potent inhibitors of osteoclastic bone resorption and the first class of drugs that unequivocally demonstrated their ability to reduce vertebral fracture risk in good-quality clinical trials (alendronate: Black et al 1996; Cummings et al 1998; risedronate: Harris et al 1999; Reginster et al 2000; ibandronate: Chesnut et al 2004; zoledronate: Black et al 2007). Today, they are often the first-line therapy for postmenopausal osteoporosis worldwide.

Additionally, alendronate and risedronate are considered to be the only antiresorptive agents shown in meta-analyses to significantly reduce the risk of non-vertebral fractures (Cranney et al 2002; Boonen et al 2005). In prospective analyses, risedronate has demonstrated to reduce hip fracture incidence (McClung et al 2001), and zoledronate recently has shown robust data for non-vertebral and hip fracture risk reduction in addition to profound effects on decreased vertebral fracture incidence (Black et al 2007).

So far, oral bisphosphonates such as alendronate, risedronatem and ibandronate have come to be the most widely used drugs in the treatment of osteoporosis, whereas the newer intravenous bisphosphonates, such as ibandronate and zoledronate, are about to round off the overall beneficial potential of bisphosphonate treatment in postmenopausal osteoporosis.

The fracture risk reduction as well as the increase in BMD and improvement of structural bone properties induced by bisphosphonates seem to be related to the profound inhibition of osteoclastic bone resorption with an initial filling of the remodeling space (resorption lacuna), followed by an increased degree of mineralization that results from the globally slowed down rate of bone turnover (Boivin et al 2000).

\section{Pharmacology of bisphosphonates}

Bisphosphonates are chemical $\mathrm{P}-\mathrm{C}-\mathrm{P}$ analogs of inorganic pyrophosphate, which is characterized by a $\mathrm{P}-\mathrm{O}-\mathrm{P}$ structure. 
Thus the $\mathrm{P}-\mathrm{C}-\mathrm{P}$ structure is resistant to enzymatic degradation by pyrophosphatase (see Figure 1).

Bisphosphonates have a high binding affinity to hydroxyapatite, are internalized by osteoclasts through endocytosis, and inhibit bone resorption by cellular effects that impair osteoclast recruitment, differentiation, and action on the bone surface (Chapurlat and Delmas 2006).

Although the various bisphosphonates share many pharmacologic features, important biochemical differences exist among them, particularly in the way in which they bind to bone mineral and their effects on bone resorption. These differences may account for some of the observed variations in potency, disease-specific efficacy, safety patterns, and speed of onset and offset of action (Russell 2007).

\section{Pharmacodynamics}

As a class, all bisphosphonates work through the binding of the phosphonate groups to hydroxyapatite. Bisphosphonates have a common $\mathrm{P}-\mathrm{C}-\mathrm{P}$ backbone, where $\mathrm{C}$ is carbon and $\mathrm{P}$ represents a phosphonate group. The presence of 2 phosphonate groups allows the molecule to act as a "bone hook" and is essential for targeting bone and for the molecular mechanism of action of the compounds.

Bisphosphonates have 2 side groups: R1 and R2. When the R1 side group is a hydroxyl group, as it is in all commonly used bisphosphonates, it enables enhanced binding to bone.

It is the differences in the R2 side group, however, that account for the significant disparities between the various bisphosphonates. Second-generation bisphosphonates contain a nitrogen side group, in the form of an amino group, whereas earlier bisphosphonates have no nitrogen group in the R2 side chain. An example of the earlier bisphosphonates is etidronate, which was the first bisphosphonate to have received approval for clinical use more than 30 years ago. Second-generation bisphosphonates include pamidronate and alendronate, characterized by free amino groups in their side chains. More complex molecules, such as risedronate, ibandronate, and zoledronate, have later been developed as a result of medicinal chemistry approaches to enhance efficacy and safety; in risedronate and zoledronate their nitrogen groups are contained within heterocyclic rings (see Table 1) (Russell 2007).

The structure of the $\mathrm{R} 2$ chain is important in determining the potency of individual bisphosphonates in biologic models, and this includes a potential role for the R2 side chain in modulating bone binding. The presence and position of nitrogen within the structure of the later-generation

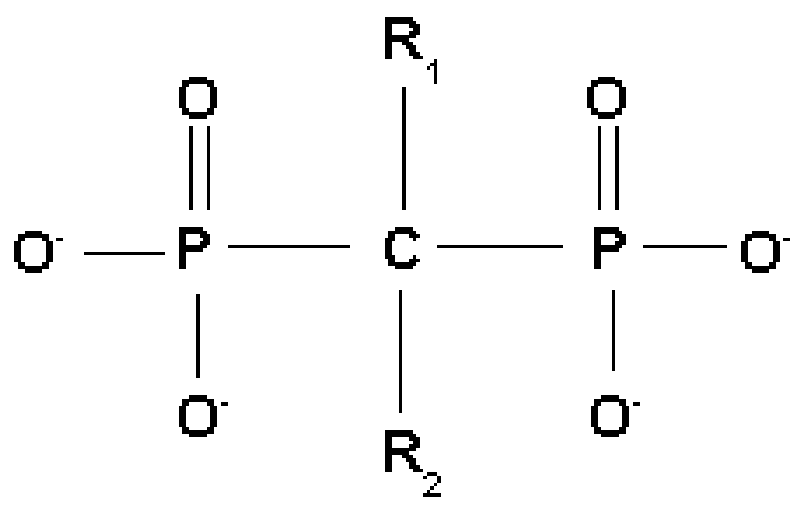

Figure I Generic bisphosphonate structure with functional domains.

bisphosphonates are directly related to their relative potency. The most recent bisphosphonates, risedronate, ibandronate, and zoledronate, are all highly potent compared with the earlier bisphosphonates. The difference in potency is probably attributable to the fact that the most recent bisphosphonates all contain nitrogen groups within their R2 side chains, which inhibits farnesyl pyrophosphate (FPP) synthase, a key enzyme located at an important branch point along the mevalonate pathway, which is critical for the production of cholesterol and isoprenoid lipids (Luckman et al 1998; Kavanagh et al 2006a, b; Russell 2007). Some of these lipids (eg, FPP and geranylgeranyl pyrophosphate) are necessary for the prenylation of some GTPases (eg, Ras, Rho, and Rac) regulating osteoclast morphology and function, cytoskeletal arrangement, membrane ruffling, lysosome trafficking, and cell survival (Ridley and Hall 1992).

In a study examining the potency of several nitrogencontaining bisphosphonates, a correlation has been found between the ability of bisphosphonates to inhibit FPP synthase in vitro and inhibit protein prenylation in cell-free extracts as well as in purified osteoclasts in vitro, and the ability to inhibit bone resorption in vivo (Dunford et al 2001). The order of potency in inhibiting FPP synthase (zoledronate $>$ risedronate $>$ ibandronate $>$ alendronate) closely matched the order of antiresorptive potency (Russell 2007).

Although bisphosphonates act mostly through inhibition of protein prenylation, their ability to adsorb to bone mineral also contributes to their antiresorptive potency and duration of action. The binding affinities of various bisphosphonates have been shown to vary according to differences in the $\mathrm{R} 2$ side chain (zoledronate $>$ alendronate $>$ ibandronate $=$ risedronate) (Nancollas et al 2005).

Thus, there are several observed differences in the clinical profile and efficacy among the bisphosphonates that underlie significant variation in their key pharmacologic 
Table I Structures of bisphosphonates, including nitrogen-containing bisphosphonates licensed for the treatment of postmenopausal osteoporosis (alendronate, ibandronate, risedronate, zoledronate)

\begin{tabular}{|c|c|c|}
\hline Agent & $\mathbf{R}_{1}$ side chain & $R_{2}$ side chain \\
\hline Etidronate & $-\mathrm{OH}$ & $-\mathrm{CH}_{3}$ \\
\hline Clodronate & $-\mathrm{Cl}$ & $-\mathrm{Cl}$ \\
\hline Tiludronate & $-\mathrm{H}$ & \\
\hline Pamidronate & $-\mathrm{OH}$ & ${ }_{2}-\mathrm{CH}_{2}-\mathrm{NH}_{2}$ \\
\hline Neridronate & $-\mathrm{OH}$ & $-\left(\mathrm{CH}_{2}\right)_{5}-\mathrm{NH}_{2}$ \\
\hline Olpadronate & $-\mathrm{OH}$ & $-\left(\mathrm{CH}_{2}\right)_{2} \mathrm{~N}\left(\mathrm{CH}_{3}\right)_{2}$ \\
\hline Alendronate & $-\mathrm{OH}$ & $-\left(\mathrm{CH}_{2}\right)_{3}-\mathrm{NH}_{2}$ \\
\hline Ibandronate & $-\mathrm{OH}$ & $-\mathrm{CH}_{2}-\mathrm{CH}_{2} \mathrm{~N}=\mathrm{CH}_{3}$ \\
\hline Risedronate & $-\mathrm{OH}$ & \\
\hline Zoledronate & $-\mathrm{OH}$ & \\
\hline
\end{tabular}

characteristics. The binding affinity to hydroxyapatite determines attachment to bone and duration of effect, and the inhibition of FPP synthase determines antiresorptive potential. The relative potency of different bisphosphonates is related to these two factors. Together, these factors combine to contribute to the overall effect of these drugs. For example, risedronate is a high-potent inhibitor of FPP synthase, but does not bind to hydroxyapatite as strongly as alendronate or zoledronate does (Dunford et al 2001; Nancollas et al 2006; Russell 2007). Risedronate would be expected to exhibit a distinct pharmacologic profile on bone, which affects remodeling processes, mineral properties, the persistence of action, and bone quality when compared with other bisphosphonates, such as alendronate and ibandronate (Russell 2007).

On the other hand, the unique pharmacologic profile of zoledronate may explain why it is possible to achieve profound and sustained suppression of bone resorption with a single, low dose of this compound. Zoledronate has a high binding affinity for bone mineral (Nancollas et al 2006). This increases the amount of drug that binds to bone and is likely to minimize the amount of drug that diffuses from bone after binding. Zoledronate is one of the most potent inhibitors of FPP synthase (Dunford et al 2001). This amplifies the antiresorptive potential of the drug and reduces the total amount of drug required in each dose (Russell 2007). Both aspects, the specific pharmacodynamic features of zoledronate as well as its once-yearly intravenous application resulting in improved "compliance", might contribute to its apparent beneficial anti-fracture efficacy.

\section{Pharmacokinetics}

Bisphosphonates have common pharmacokinetic properties, including poor intestinal absorption, high affinity for bone mineral, inhibitory effects on osteoclastic bone resorption, prolonged bone retention, and elimination in the urine (Fleisch 1997).

Intestinal absorption is low with $0.6 \%-3 \%$ of the orally given bisphosphonate and furthermore impaired by food - especially foods containing calcium - so oral bisphosphonates should be given when fasting, just with plain water. Especially calcium and magnesium salts impair intestinal absorption of oral bisphosphonates (Chapurlat and Delmas 2006). The patient should fast for at least 30 minutes (alendronate, risedronate) or even 60 minutes (ibandronate) after taking oral bisphosphonates. This, of course, does not apply to intravenous bisphosphonates that do not require any special specifications for their application.

The plasma protein binding is low, and plasma half-life time of bisphosphonates is short. Approximately $40 \%-60 \%$ of the dose is concentrated in the skeleton, depending on the rate of bone turnover and the type of bisphosphonate, and the remaining amount is excreted, unaltered, in the urine.

Bisphosphonates in general stay embedded in bone for a very long time. However, there are significant differences in their effective biologic half-life explained by the binding affinity of these drugs. Bisphosphonates can be detected in body fluids months after administration. Higher-affinity bisphosphonates should be detectable for longer periods because of their greater capacity to recycle at the bone surface; for example, the terminal half-life of alendronate in humans has been estimated to be about 10 years (Russell 2007).

The suppressive effect of bisphosphonates on bone resorption is delayed by at least 1-2 days, in contrast to the more rapid effect of calcitonin. Both the concentration of bisphosphonate present in bone mineral at any time and the total dose administered over a long period of time, seem to be important for the magnitude of the reduction in bone turnover (Lin et al 1992, 1993; Papapoulos 2001; Riis et al 2001; Tankó et al 2003).

No serum metabolite of bisphosphonates has been described so far. Nitrogen-containing bisphosphonates seem to bind to plasma proteins, and some of them are eliminated by a renal tubular secretory mechanism (Lin et al 1992, 1993). Drug inter-actions are limited to aminoglycoside 
antibiotics, with which severe hypocalcaemia can occur (Pedersen-Bjergaard and Myhre 1991).

\section{Anti-fracture efficacy}

The aim of pharmacologic interventions in osteoporosis is to reduce the risk of its complications - of vertebral and hip fractures as well as all non-vertebral fractures. The gold standard for demonstration of anti-fracture efficacy in osteoporosis trials is the primary, predetermined analysis of the intention to treat (ITT) population; this is highlighted by the requirement of fracture prevention efficacy in trials of at least 3 years' duration for registration of new therapies (FDA 1994; CPMP 2001). The majority of these trials have focused on the prevention of vertebral fracture, with assessment of efficacy in the prevention of non-vertebral fracture relying largely on the analysis of subgroups. The use of subgroup analyses to demonstrate efficacy of a new treatment is not in line with recognized scientific standards and should be interpreted with caution. Indeed, the guidelines from the International Conference on Harmonization (ICH) of Technical Requirements for Registration of Pharmaceuticals for Human Use (EMEA 1998) explicitly state that such analyses should be used in an exploratory manner only and that conclusions as to the efficacy of a treatment should not be based on such analyses alone (Boonen et al 2005).

Oral alendronate and risedronate have been used in the treatment of postmenopausal osteoporosis for many years, with a daily dosage regimen. Later, they came to be marketed with weekly dosage regimens. Ibandronate is now available for use in an oral monthly dosage regimen and in an intravenous quarterly injection. All the approvals for non-daily and/or non-oral regimens of alendronate, risedronate, and ibandronate have been based on results of so-called bridging studies only.

Most recently, zoledronate, with the once-yearly intravenous application (15 minutes' infusion), was licensed for the treatment of postmenopausal osteoporosis. The anti-fracture efficacy of these four nitrogen-containing bisphosphonates is summarized in Table 2 (vertebral fractures) and Table 3 (non-vertebral fractures).

All these agents have documented efficacy in reducing the risk of vertebral fractures. Based on this proven risk reduction, bisphosphonates are the drug treatment of first choice in postmenopausal osteoporosis in most countries worldwide.

The anti-fracture efficacy has been established in large outcome trials of 3-4 years' duration, but long-term fracture data in major study populations are missing. Some patients in the initial phase III trials were followed up subsequently, and the data of 10 years of treatment with alendronate in the FLEX study (Black et al 2006), as well as 7 years' data with risedronate (Mellström et al 2004), showed a continuous increase in lumbar spine and total hip BMD.

In the FLEX study ( $n=1099)$, women who discontinued alendronate after 5 years showed a moderate decline in BMD and a gradual rise in biochemical markers but no higher fracture risk, other than for clinical vertebral fractures, compared with those who continued alendronate. The authors concluded from these results that, for many women, discontinuation of alendronate for up to 5 years did not appear

Table 2 Vertebral fracture incidence by treatment (ITT populations in fracture outcome studies of 3 years)

\begin{tabular}{|c|c|c|c|c|c|}
\hline \multirow{2}{*}{$\frac{\text { Drug }}{\text { Trial (total n) }}$} & \multirow[t]{2}{*}{ Authors } & \multicolumn{2}{|c|}{ Fracture incidence (\%) } & \multirow{2}{*}{$\frac{\text { Treatment effect }}{R R(95 \% \mathrm{Cl})}$} & \multirow[t]{2}{*}{$\mathrm{p}$ value } \\
\hline & & placebo & active & & \\
\hline \multicolumn{6}{|l|}{ Alendronate } \\
\hline FIT VFA $(2,027)$ & Black et al 1996 & 15.0 & 8.0 & $0.53(0.41,0.68)$ & $<0.001$ \\
\hline FIT CFA $(4,432)^{*}$ & Cummings et al 1998 & 3.8 & 2.1 & $0.56(0.39,0.80)$ & 0.002 \\
\hline \multicolumn{6}{|l|}{ Risedronate } \\
\hline VERT-NA $(2,458)$ & Harris et al 1999 & 16.3 & $11.3^{+}$ & $0.59(0.42,0.82)$ & 0.003 \\
\hline VERT-MN $(I, 226)$ & Reginster et al 2000 & 29.0 & $18.1^{+}$ & $0.5 I(0.36,0.73)$ & $<0.001$ \\
\hline \multicolumn{6}{|l|}{ Ibandronate } \\
\hline BONE $(2,946)$ & Chesnut et al 2004 & 9.6 & $4.7^{\#}$ & $0.38(0.25,0.59)$ & 0.0001 \\
\hline \multicolumn{6}{|l|}{ Zoledronate } \\
\hline HORIZON-PFT $(7,765)$ & Black et al 2007 & 10.9 & 3.3 & $0.30(0.24,0.38)$ & $<0.001$ \\
\hline
\end{tabular}

$\mathrm{RR}(95 \% \mathrm{Cl})=$ relative risk and $95 \%$ confidence interval. $\mathrm{RR}(95 \% \mathrm{Cl})$ for ibandronate was estimated.

*FIT CFA trial duration was 4 years.

${ }^{+}$Fracture incidence quoted for risedronate reflects the $5 \mathrm{mg}$ daily group only.

\#Fracture incidence quoted for ibandronate reflects the $2.5 \mathrm{mg}$ daily group only. 
Table 3 Non-vertebral fracture incidence by treatment (ITT populations in fracture outcome studies of 3 years) (Modified and supplemented after Boonen et al 2005)

\begin{tabular}{|c|c|c|c|c|c|}
\hline \multirow{2}{*}{$\frac{\text { Drug }}{\text { Trial (total } n)}$} & \multirow[t]{2}{*}{ Authors } & \multicolumn{2}{|c|}{ Fracture incidence (\%) } & \multirow{2}{*}{$\frac{\text { Treatment effect }}{\mathrm{RR}(95 \% \mathrm{Cl})}$} & \multirow[t]{2}{*}{ p value } \\
\hline & & placebo & active & & \\
\hline \multicolumn{6}{|l|}{ Alendronate } \\
\hline FIT VFA $(2,027)$ & Black et al 1996 & 14.7 & 11.9 & $0.80(0.63,1.01)$ & 0.063 \\
\hline FIT CFA $(4,432) *$ & Cummings et al 1998 & 13.3 & 11.8 & $0.88(0.74,1.04)$ & 0.130 \\
\hline \multicolumn{6}{|l|}{ Risedronate } \\
\hline VERT-NA $(2,458)$ & Harris et al 1999 & 8.4 & $5.2^{+}$ & $0.60(0.39,0.94)$ & 0.020 \\
\hline VERT-MN $(1,226)$ & Reginster et al 2000 & 16.0 & $10.9^{+}$ & $0.67(0.44,1.04)$ & 0.063 \\
\hline $\operatorname{HIP}(9,331)$ & McClung et al 200I & 11.2 & 9.4 & $0.80(0.70,1.00)$ & 0.030 \\
\hline \multicolumn{6}{|l|}{ Ibandronate } \\
\hline BONE $(2,946)$ & Chesnut III et al 2004 & 8.2 & $9.1^{\#}$ & I.II $(0.83,1.48)$ & not available \\
\hline \multicolumn{6}{|l|}{ Zoledronate } \\
\hline HORIZON-PFT $(7,765)$ & Black et al 2007 & 10.7 & 8.0 & $0.75(0.64,0.87)$ & $<0.001$ \\
\hline
\end{tabular}

$\mathrm{RR}(95 \% \mathrm{Cl})=$ relative risk and $95 \%$ confidence interval. $\mathrm{RR}(95 \% \mathrm{Cl})$ for ibandronate is estimated.

*FIT CFA trial duration was 4 years.

${ }^{+}$Fracture incidence quoted for risedronate reflects the $5 \mathrm{mg}$ daily group only.

\#Fracture incidence quoted for ibandronate reflects the $2.5 \mathrm{mg}$ daily group only.

to significantly increase fracture risk. However, women at very high risk of clinical vertebral fractures may benefit by continuing beyond 5 years (Black et al 2006).

In the 6-7 years extension $(n=164)$ to 3 years vertebral fracture study, annualized incidence of new vertebral fractures did not change in the 7 -year risedronate group during the 6-7 years compared with 4-5 years, while a significant reduction was observed in the placebo group that switched to risedronate treatment during years 6-7 (Mellström et al 2004). Nevertheless, a lower scientific value of the latter studies must be considered. Other extension studies with ibandronate and zoledronate are ongoing and their data should be available shortly.

The anti-fracture efficacy of most nitrogen-containing bisphosphonates available for postmenopausal osteoporosis, namely alendronate, risedronate, and ibandronate, was established in trials on daily oral dosage regimens and in case of ibandronate with an intermittent, but not licensed oral regimen (20 mg every other day for the first 24 days, followed by 9 weeks without treatment). Weekly oral dosage regimens with alendronate $70 \mathrm{mg}$ (Rizzoli et al 2002) and risedronate $35 \mathrm{mg}$ (Brown et al 2002), monthly oral ibandronate $150 \mathrm{mg}$ (Reginster et al 2006), and intravenous ibandronate $3 \mathrm{mg}$ every 3 months (Delmas et al 2006), respectively, have been shown in non-inferiority studies to result at least in not significantly different, or even higher increases in lumbar spine, femoral neck, or hip BMD compared with the proven oral daily regimens. These bridging studies are aimed at showing that a new regimen is at least as effective as a reference regimen (non-inferiority) with the same compound through the use of a surrogate marker, usually BMD. One- or 2-year duration for bridging studies can be accepted for a given compound, provided there is sufficient evidence to support a good correlation between early changes in the chosen surrogate endpoint (eg, BMD or biochemical markers changes) and long-term (up to 3 years) fracture risk reduction. However, safety studies with longer duration may be needed (Reginster et al 2006). In general, bridging studies cannot provide evidence on the same level as original study protocols on fracture risk (limited patient number and duration).

In fact, zoledronate, with its licensed intravenous dosage of $5 \mathrm{mg}$ once yearly, is the only compound that has directly been investigated for fracture outcomes in a study using non-daily administration.

For non-spine fracture, even in trials assessing them as a primary endpoint, differences in study design, randomized population, and varying definitions of what constitutes a non-vertebral fracture can influence outcomes. In addition, falls and fall-related risk factors have never been controlled for in or between individual studies (Miller 2008). Only risedronate and zoledronate have been proven to reduce the risk of non-vertebral fractures in general, and of hip fractures in particular, in the ITT populations from randomized trials of at least 3 years' duration. Furthermore, both risedronate and very recently also zoledronate have been shown to provide non-vertebral anti-fracture efficacy in more than one study (RIS: Harris et al 1999; McClung et al 2001; ZOL: Black et al 2007; Lyles et al 2007). 
Additionally, meta-analyses of alendronate, as well as those of risedronate, have shown evidence of being efficacious in preventing non-vertebral fracture (Boonen et al 2005). The use of data only from ITT populations in this meta-analysis, while likely to result in conservative estimates of the overall reduction in relative risk of fracture, ultimately gives the most reliable overall estimate of treatment efficacy.

Otherwise, the only evidence for the non-vertebral anti-fracture efficacy of ibandronate so far is a post-hoc subgroup analysis from the BONE study suggesting that non-vertebral fracture risk might be reduced in patients with the lowest baseline BMD at the femoral neck with a $\mathrm{T}$ score below -3.0 SD (Chesnut et al 2004).

Although a direct comparison of one bisphosphonate with another cannot be made in the absence of head-to-head studies of fracture outcome, the magnitude of effect with zoledronate (fracture risk reduction for vertebral, non-vertebral and hip fractures of $75 \%, 25 \%$ and $40 \%$ respectively) appears to be at least similar to, and possibly better than, that reported for other interventions (Compston 2007). Most robust data exist with zoledronate in intravenous dosage regimens, and with risedronate in oral dosage regimens.

Many comparative studies have investigated the effect magnitudes of different bisphosphonates on bone markers and bone mineral density, eg, the FACT study comparing alendronate and risedronate efficacy on such a basis (Reid et al 2006). These trials might offer additional information, but they have not been able to make up for the lack of comparative outcome studies on fracture incidence. Therefore, the authors will not reflect on these surrogate parameter studies, since there is no evidence for a sufficient correlation between bone marker reduction and BMD increase on the one hand, and the overall fracture reduction among the different bisphosphonates on the other hand. The same applies to studies using observational data derived from commercially available datasets to compare fracture risk reduction of different bisphosphonates, eg, the REAL study comparing the reduction of early fracture risk of alendronate vs risedronate treatment (Silverman et al 2007). The conclusion that risedronate is more effective than alendronate, however, has limited justification. Although prospective, observational studies often provide preliminary data about the effectiveness of certain therapies, randomized placebo-controlled trials remain the gold standard for evaluating drug efficacy (Black and Rosen 2007).

\section{Health-related quality of life}

Over the last 30 years, health-related quality of life (HRQOL) has emerged as an important attribute of clinical investigation and patient care, and is now a key component of what has recently come to be known as "patient-reported outcomes". Given the impact of incident vertebral and/or hip fractures on HR-QOL, it might be expected that a therapy reducing the incidence of such fractures would result in a relatively better quality of life (McCloskey 2006). Otherwise, a recent review of utility values for osteoporotic fractures to be used in economic analyses has highlighted the remarkably few studies on the impact of osteoporotic fractures (Brazier et al 2002).

Until today, studies showing a direct effect of an antiosteoporotic treatment, including nitrogen-containing bisphosphonates, on HR-QOL have been very rare. Statistical power is inadequate to demonstrate effects on HR-QOL in the majority of pivotal studies, which are usually designed to show a reduction in vertebral fracture risk (McCloskey 2006).

In the Fracture Intervention Trial (FIT) of alendronate in 2027 postmenopausal women aged 55 to 81 years with low femoral neck bone density and a preexisting vertebral fracture, alendronate therapy for 3 years reduced the number of days of bed disability and the number of days of limited activity caused by back pain (Nevitt et al 2000). Irrespective of the treatment assignment, women with new clinically recognized vertebral fractures during follow-up experienced a higher risk in terms of the number of days of bed disability and of limited activity because of back pain after the fracture. Women receiving alendronate reported an average of 3.2 fewer days of bed rest $(p=0.001)$ and 11.4 fewer days of limited activity (not including days of bed rest) because of back pain $(p=0.04)$ during follow-up than those receiving placebo. In the alendronate group, relative to the placebo group, there was a reduced risk of 1 or more bed-rest days (relative risk $0.68 ; 95 \%$ confidence interval [CI] 0.53-0.87), of 7 or more bed-rest days $(0.44 ; 0.30-0.64)$, and of 7 or more limited-activity days $(0.87 ; 0.76-0.99)$.

In an actual review on ibandronate and other bisphosphonates, the authors conclude that ibandronate offers an effective and convenient choice for the relief of bone pain in a variety of diseases with increased bone turnover (Ringe and Body 2007). This has widely been proven for malignant conditions, but, in contrast, there are only very limited data available on pain relief in non-malignant conditions as corticosteroid-induced osteoporosis, localized transient osteoporosis (bone marrow edema) and sternocostoclavicular hyperostosis.

Data for HR-QOL and mortality have been published recently from two trials of the HORIZON study program 
with zoledronate, the Pivotal Fracture Trial (PFT) (Black et al 2007) and the Recurrent Fracture Trial (RFT) (Lyles et al 2007). In the HORIZON-PFT, 3889 postmenopausal women (mean age, 73 years) were randomly assigned to receive a single 15 -minute infusion of zoledronate $(5 \mathrm{mg})$ and 3876 were assigned to receive placebo at baseline, at 12 months, and at 24 months; the patients were monitored for 36 months. The once-yearly infusion of zoledronate during a 3-year period significantly reduced the risk of vertebral, hip, and other fractures. In an interim analysis in 2005, the authors reported also fewer days of limited activity due to back pain or fractures in zoledronate patients compared to placebo: 61 vs 72 days $(p=0.0076)$, and 6 vs 10 days $(p=0.001)$, respectively (Black et al 2006).

\section{Reduction of mortality (zoledronate)}

The only study so far demonstrating improved survival in treated osteoporosis patients is the HORIZON-RFT with zoledronate (Lyles et al 2007). In this randomized, doubleblind, placebo-controlled trial in men and women after hip fracture, 1065 patients were assigned to receive yearly intravenous zoledronate (at a dose of $5 \mathrm{mg}$ ), and 1062 patients were assigned to receive placebo. The infusions were first administered within 90 days after surgery for a hip fracture. In this event-driven study (new clinical fractures), the median follow-up was 1.9 years. The rates of any new clinical fracture were $8.6 \%$ in the zoledronate group and $13.9 \%$ in the placebo group, a $35 \%$ risk reduction with zoledronate $(\mathrm{p}=0.001)$; the respective rates of a new clinical vertebral fracture were $1.7 \%$ and $3.8 \%(p=0.02)$, and the respective rates of new non-vertebral fractures were $7.6 \%$ and $10.7 \%(\mathrm{p}=0.03)$. In the safety analysis, 101 of 1054 patients in the zoledronate group (9.6\%) and 141 of 1057 patients in the placebo group $(13.3 \%)$ died, a reduction of $28 \%$ in deaths from any cause in the zoledronate group $(\mathrm{p}=0.01)$ (see Figure 2).

\section{Safety}

\section{General safety}

Evidence supports a good safety profile for nitrogen-containing bisphosphonates in postmenopausal osteoporosis. Nevertheless, some tolerability issues have been associated with their use. Upper gastrointestinal (UGIT) adverse events (AEs) in oral bisphosphonates, renal toxicity, influenza-like illness, and osteonecrosis of the jaw, uveitis, and also atrial fibrillation have been reported and should be considered. Strampel et al (2007) provided recently an overview of the safety issues associated with the nitrogen-containing bisphosphonates and discussed the potential effect of these issues on adherence.
In clinical trials, UGIT AEs, including severe events such as esophageal ulcer, esophagitis, and erosive esophagitis, have been reported at similar frequencies in placeboand active-treatment arms. In a randomized, head-to-head comparison of alendronate and risedronate, the overall incidence of clinical AEs was similar for both compounds (Rosen et al 2005). However, post-marketing studies have highlighted UGIT AEs as a concern. These studies show that a significant portion of patients is less compliant with administration instructions outside strict clinical trial supervision, and when oral bisphosphonates are not administered as directed, patients are more likely to experience UGIT AEs. Some clinical trials with oral bisphosphonates have suggested that a decrease in the frequency of administration may lead to improvement in gastrointestinal tolerability. UGIT intolerability can be minimized by explaining to the patient and/or caregiver the importance of following administration instructions (Strampel et al 2007).

With intravenous bisphosphonate application, venous irritation or thrombophlebitis might be encountered. Intravenous bisphosphonates offer an alternative regimen for patients with osteoporosis. Modern nitrogen-containing IV bisphosphonates (ie, ibandronate, zoledronate) have also shown a better safety profile in relation to renal toxicity (Chang et al 2003; Delmas et al 2006; Black et al 2007; Lyles et al 2007) compared with earlier substances (eg, etidronate, clodronate) (Bounameaux et al 1983). AEs on renal function with dosages used for postmenopausal osteoporosis are generally rare and primarily related to infusion rate and dose. Due to lack of data, no conclusions can be made about bisphosphonate safety in patients with intrinsic renal disease or an estimated glomerular filtration rate of $<30 \mathrm{~mL} / \mathrm{min}$ (Lewiecki and Miller 2007).

Influenza-like illness, often referred to as an acute-phase reaction, covers symptoms such as fatigue, fever, chills, myalgia, and arthralgia. These symptoms are transitory and self-limiting and usually do not recur after subsequent drug administration (Strampel et al 2007). Symptoms of influenza-like illness have been associated with both IV and oral bisphosphonates (Delmas et al 2006; Black et al 2007; Bock et al 2007).

In the HORIZON-PFT with zoledronate, the number of patients who had arrhythmia in the zoledronic-acid group (266 patients, or 6.9\%) was significantly higher than that in the placebo group (203 patients, or $5.3 \%$; $\mathrm{p}=0.003$ ). Serious atrial fibrillation, as a subcategory of all arrhythmias, was more common among patients in the zoledronic acid group. Otherwise, there was no difference in arrhythmia 


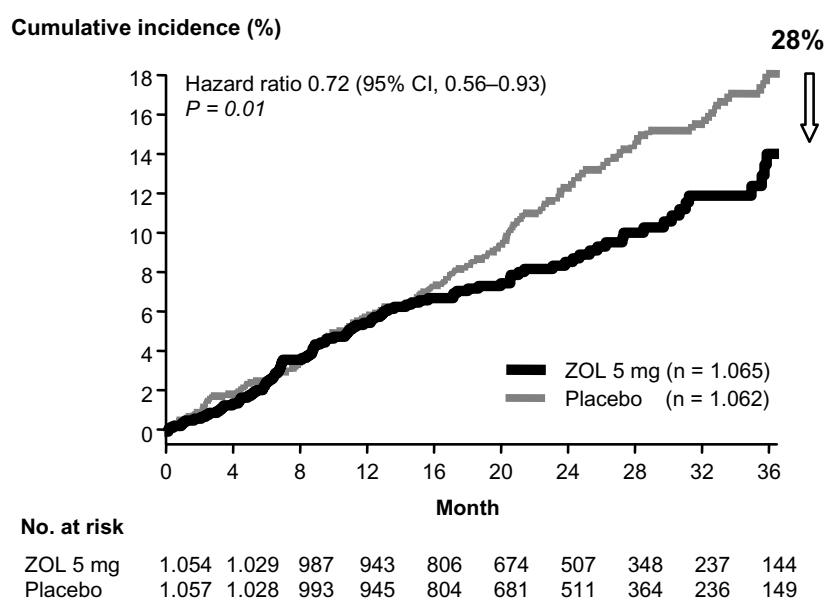

Figure 2 Mortality as a secondary endpoint in the HORIZON-RFT (Recurrent Fracture Trial) with zoledronate: in the safety analysis, a total of 242 of 21 I I patients (1 I.5\%) died during the study, $10 \mathrm{I}$ of 1054 (9.6\%) were in the zoledronate group and $14 \mathrm{I}$ of 1057 (13.3\%) were in the placebo group (hazard ratio for the zoledronate group, 0.72; 95\% Cl, 0.56-0.93; $\mathrm{p}=0.0 \mathrm{I})$. Adapted with permission from Lyles $\mathrm{KW}$, Colón-Emeric CS, Magaziner JS, et al. 2007. Zoledronic acid and clinical fractures and mortality after hip fracture. N Engl J Med, 357:1799-809. Copyright (C) 2007 Massachusetts Medical Society. All rights reserved.

related complications (eg, strokes). Furthermore, no time relationship to the zoledronate infusion was observed. The events were uniformly distributed over time, with the vast majority of events occurring more than 30 days after infusion, by which time zoledronate was undetectable in the circulation (Black et al 2007). There is no further evidence for an increased risk of serious atrial fibrillation with zoledronate, neither from other clinical trials in malignant conditions or osteoporosis - rather to the contrary (Lyles et al 2007) - nor from the extensive postmarketing experience in over 1.5 million tumor patients receiving 2-10 times higher dosages per year, compared with the once-yearly $5 \mathrm{mg}$ dose used in postmenopausal osteoporosis. Nevertheless, in a letter to the editor, published in the same issue of the New Engl J Med as the HORIZON-PFT data, Cummings et al (2007) reported on their observations on atrial fibrillation in the FIT with alendronate. The overall risk of atrial fibrillation AEs in FIT was similar between alendronate and placebo ( 2.5 vs $2.2 \% ; p=0.42$ ). Looking only at atrial fibrillation AEs that were serious, the incidence was numerically higher with alendronate ( 1.5 vs $1.0 \% ; \mathrm{p}=0.07$ ), but not statistically significant (Cummings et al 2007). In general, there is no pharmacologic mechanism known and also no repeated evidence from clinical trials or post-marketing observation so far indicating a medical concern based on a possible causality between bisphosphonate use and increased risk for serious atrial fibrillation.

\section{Bone safety}

Osteonecrosis of the jaw (ONJ) has also been associated with nitrogen-containing bisphosphonates, particularly in tumor patients treated with high IV doses. A small number of patients with osteoporosis using oral bisphosphonates have also reported this AE. A multidisciplinary expert group of the American Society for Bone and Mineral Research (ASBMR) reviewed all pertinent published data on bisphosphonateassociated ONJ as well as the Food and Drug Administration's (FDA) drug adverse event reports. A case definition was developed so that subsequent studies could report on the same condition. The task force defined ONJ as the presence of exposed bone in the maxillofacial region that did not heal within 8 weeks after identification by a health care provider. Based on review of both published and unpublished data, the risk of ONJ associated with oral bisphosphonate therapy for osteoporosis seems to be low, estimated at 1 in 10,000 to 100,000 patient-treatment years. However, the task force recognized that information on incidence of $\mathrm{ONJ}$ is rapidly evolving and that the true incidence may be higher. The risk of ONJ in patients with cancer treated with high doses of intravenous bisphosphonates is clearly higher in the range of 1-10 per 100 patients (depending on duration of therapy) (Khosla et al 2007). These estimates are also supported by repeated interim analyses from the German central ONJ register (Felsenberg et al 2006).

Post-marketing experience with IV bisphosphonates in postmenopausal osteoporosis remains limited. There have been no data so far from clinical studies using IV ibandronate or zoledronate in this condition indicating any increased risk for ONJ, as observed in patients with malignant conditions. In the HORIZON-PFT with zoledronate, eg, there were no spontaneous reports of ONJ. From a research of the trial database of AEs, followed by expert adjudication, 2 cases of potential ONJ were identified ( 1 in the placebo group, 1 in the zoledronic acid group). In both patients delayed healing followed surgical manipulation and was subsequently resolved with antibiotic therapy and débridement (Black et al 2007).

Another aspect of bone safety in long-term bisphosphonate use has been discussed for several years. In general, slowed bone remodeling and an increased degree of mineralization are presumed to result in an improved bone quality, with greater bone strength as a consequence (Chapurlat and Delmas 2006). Prolonged use of bisphosphonates at high doses might be associated, however, with the accumulation of micro-cracks. Indeed, in Beagle dogs receiving risedronate $(5 \mathrm{mg} / \mathrm{kg}$ body weight daily) or alendronate $(10 \mathrm{mg} / \mathrm{kg}$ body weight daily) for 1 year, micro-damage accumulation has been described by 
David Burr's group in ribs (Mashiba et al 2005) and vertebrae (Mashiba et al 2001). Simultaneously, trabecular bone volume and vertebral strength increased significantly, while toughness tended to be reduced. Micro-damage accumulation was also shown in the vertebrae of Beagle dogs receiving a high dose of incadronate, while vertebral strength improved and vertebral toughness was reduced (Komatsubara et al 2003). The clinical significance of these findings, however, remains unclear since the doses of bisphosphonates used in these animal studies were about 6-fold greater than those used in the treatment of humans, and some parameters of bone quality were improved, while others tended to deteriorate slightly (Chapurlat and Delmas 2006). Another study examined the occurrence of micro-cracks in the bones of Beagle dogs receiving risedronate or alendronate at doses comparable to those used in humans for the treatment of osteoporosis. These results indicated an increased micro-damage accumulation, but without significant negative effects on the mechanical properties of bone (Allen et al 2005). Otherwise, the authors showed very recently that neither risedronate nor alendronate treatment in Beagle dogs altered the strength-density relationship compared with vehicle, suggesting that increases in vertebral strength with bisphosphonate treatment are explained by increased density. The energy absorption-density relationship was altered by alendronate, resulting in significantly lower energy absorption capacity at a given areal bone mineral density (aBMD) compared with both vehicle $(-22 \%)$ and risedronate $(-14 \%)$. In accordance with the stated conclusions, these data document that after adjusting for increased aBMD, vertebrae from animals treated with bisphosphonates have similar strength as those from untreated animals. Conversely, when adjusted for increased aBMD, alendronate treatment, but not risedronate treatment, significantly reduces the energy required for vertebral fracture and is indicative of an alteration in bone quality (Allen and Burr 2008).

However, as no obvious mineralization defect was observed in bone biopsies collected from women who had received alendronate for 10 years in the FLEX trial with alendronate in postmenopausal women (Recker et al 2004), despite their markedly suppressed bone turnover, there is currently no evidence of substantial bone safety concern of bisphosphonates administered in the long term (Chapurlat and Delmas 2006).

\section{Bisphosphonates in clinical practice The problem of non-adherence}

International treatment guidelines recommend the use of bisphosphonates as first-line therapy due to their proven efficacy in fracture risk reduction and overall beneficial safety profile. Achievement of optimal treatment results in individual patients requires a long-term treatment with these substances for at least 3-5 years. Otherwise, the effectiveness of treatments for chronic conditions is compromised by suboptimal adherence, compliance and persistence with treatment in general, and in asymptomatic diseases, in particular (Christensen et al 1997; Miller 1997; Benner et al 2002).

Compliance describes the quality of intake of a given medication and considers the extent to which a dosing regimen and its associated instructions are followed. Compliance can often be quantified by a surrogate measure, the medication-possession ratio (MPR), which is the number of days of available medication divided by the number of days of study follow-up. Persistence describes the length of time patients continue to take their medication, and is defined as the time from treatment initiation to treatment completion/discontinuation. Adherence is a summary term that is determined by compliance and persistence of medication intake and describes the extent and the quality of medication intake (see Figures 3 and 4) (Badamgarav and Fitzpatrick 2006; Payer et al 2007). Adherence to medication in postmenopausal osteoporosis is in line with the general finding of low persistence rates in other chronic diseases (Reginster and Rabenda 2006).

A number of studies (Papaioannou et al 2003; Segal et al 2003; Yood et al 2003; Caro et al 2004) have reported poor levels of compliance and persistence with commonly used drug therapies for osteoporosis including bisphosphonates (Cramer et al 2007).

Approximately half of all patients do not take oral bisphosphonates regularly (Lombas et al 2001) or continue with treatment (McCombs et al 2004) for at least 12 months, with many discontinuing soon after initiation (Weycker et al 2006). While less frequent dosing regimens have significantly improved compliance and persistence, adherence to treatment remains suboptimal (Brankin et al 2006; Cramer et al 2006) and is likely to be compromising the benefits of reduced fracture risk demonstrated in clinical trials (Adachi et al 2007).

Based on several reviews, the World Health Organization estimated that long-term adherence in chronic disease averages only 50\% (WHO 2003b). It seems that this is particularly true for diseases such as postmenopausal osteoporosis that have few or no clinical symptoms, as the patient does not experience ill effects from the disease or the subsequent benefit from treatment. In the treatment of osteoporosis, 


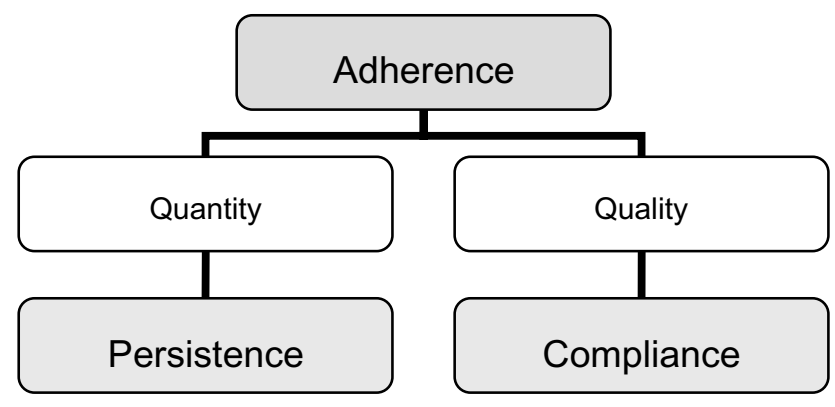

Figure 3 Adherence and its components. Adapted with permission from Payer J, Killinger Z, Sulková I, Celec P.2007.Therapeutic adherence to bisphosphonates. Biomed Pharmacother, 61:191-3. Copyright (C) 2007 Elsevier.

non-adherence to bisphosphonate therapy negatively impacts upon treatment outcomes (Reginster and Rabenda 2006). First of all, a poor adherence results in a significantly higher rate of vertebral and non-vertebral fractures, compared with that observed in adherent patients, and is associated with a decreased quality of life (Caro et al 2004; Sebaldt et al 2004; Harris et al 2005; Siris et al 2006). Non-adherence to bisphosphonates also increases the risk of hospitalization associated with osteoporotic fractures (Goettsch et al 2005) and the incidence of secondary complications associated with fractures, such as pain, nosocomial infections, and pulmonary thromboembolism, leading to higher healthcare costs (Reginster and Rabenda 2006).

In order to characterize the relationships between adherence (compliance and persistence) to bisphosphonate therapy and risk of specific fracture types in postmenopausal women, Siris et al (2006) collected data from 2 claims databases in the US during a 5-year period. Claims from 35,537 women (age, $\geq 45$ years) receiving an alendronate or risedronate prescription were evaluated for 6 months before the index prescription and during 24 months of follow-up to determine osteoporotic fractures, persistence (no gap in refills for $>30$ days during 24 months), and refill compliance (MPR $\geq 0.80$ ). Only 43\% were refill compliant, and 20\% persisted with bisphosphonate therapy during the 24-month study period. Total, vertebral, non-vertebral, and hip fractures were significantly lower in refill-compliant and persistent patients, with relative risk reductions of $20 \%-45 \%$. There was a progressive relationship between refill compliance and fracture risk reduction, commencing at refill compliance rates of approximately $50 \%$ and becoming more pronounced at compliance rates of $75 \%$ and higher (see Figure 5).

Penning-van Beest et al (2007) analyzed 8822 new female users (age, $\geq 45$ years) of alendronate or risedronate with a total of 22,484 person-years of follow-up. Patients were identified from the PHARMO Record Linkage System (PHARMO-RLS) of the Netherlands, including drug-dispensing and hospitalization data of about 2 million residents, and were followed until first hospitalization for an osteoporotic fracture, death, or end of study period. Compliance with bisphosphonates during follow-up was measured over 90-day intervals using MPR. Non-compliant bisphosphonate use was associated with a $45 \%$ increased fracture risk compared to compliant use (MPR $\geq 80 \%$ ). Classifying compliance into 5 categories, fracture risk gradually increased with poorer compliance ( $p$-value $<0.05$ for trend). A

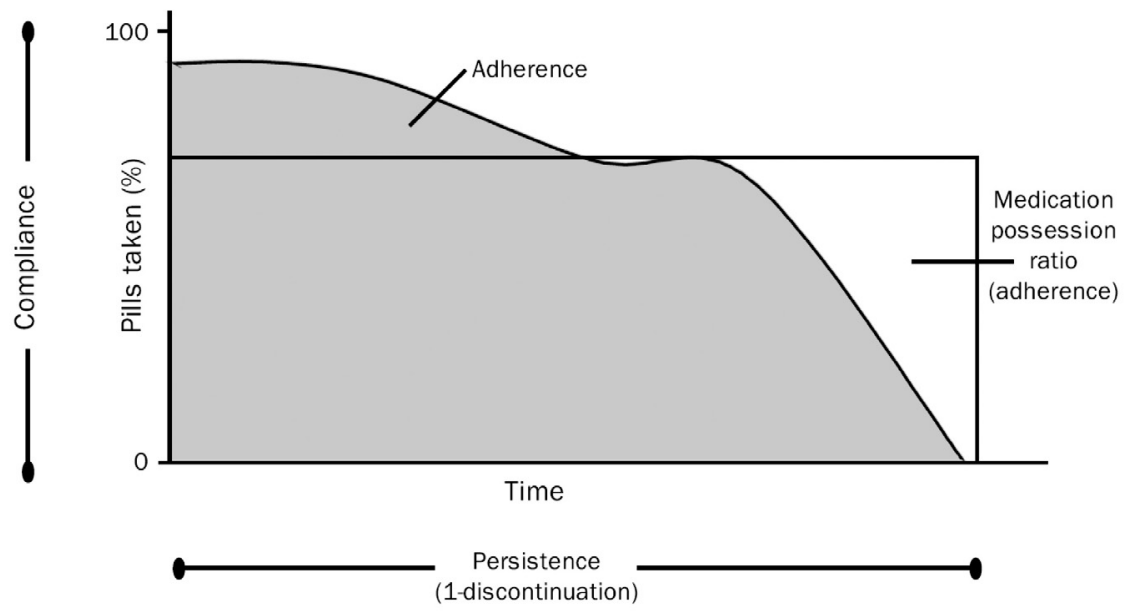

Figure 4 Persistence refers to the duration of time during which a medication is taken. Compliance is the proportion of medication taken at a given time according to instructions while persistent. Adherence represents compliance over time and can be estimated within discrete periods using the medication possession ratio. Reproduced with permission from Badamgarav E, Fitzpatrick LA. 2006.A new look at osteoporosis outcomes: the influence of treatment, compliance, persistence, and adherence. Mayo Clin Proc, 81:1009-12. Copyright (C) 2006 Mayo Foundation for Medical Education and Research.All rights reserved. 
MPR $<20 \%$ was associated with an $80 \%$ increased fracture risk compared with a MPR $\geq 90 \%$.

A retrospective cohort study of 17,988 new alendronate or risedronate users (age, $\geq 40$ years) analyzed pharmacy and medical claims data from 45 large US employers (Briesacher et al 2007). After $1-3$ years of follow-up, only 30.6\%-42.9\% of patients could achieve high compliance $(80 \%-100 \%)$, $17.4 \%-23.0 \%$ moderate compliance (79\%-40\%), and $33.8 \%-52.0 \%$ had low compliance $(0 \%-39 \%)$. Multivariate models of fracture risk showed benefits with compliance levels of at least $60 \%$. Indicated health care costs were significantly lower $(\mathrm{p}<0.05)$ in high to moderate compliant patients with total costs savings of US\$859-US\$366 per year. Although reductions in fracture risk could be detected in individuals achieving as little as $60 \%$ compliance with bisphosphonates, as many as $34 \%$ of patients in the first year of therapy and $52 \%$ by the third year did not reach even these minimal compliance levels required to receive benefits.

Another recent study was performed in Belgium to investigate adherence to bisphosphonate therapy and its specific impact on the risk of hip fracture using the Belgian national social security database (Rabenda et al 2007). Patients enrolled in the study were postmenopausal women, naïve to bisphosphonates, who received first prescription of alendronate. After 12 months, the rate of persistence was $39.45 \%$. For each decrease of the MPR by $1 \%$, the risk of hip fracture increased by $0.4 \%$ (odds ratio 0.996 ; 95\% CI 0.994-0.998; $\mathrm{p}<0.001)$. The relative risk reduction for hip fractures was $60 \%$ (hazard ratio $0.404 ; 95 \%$ CI

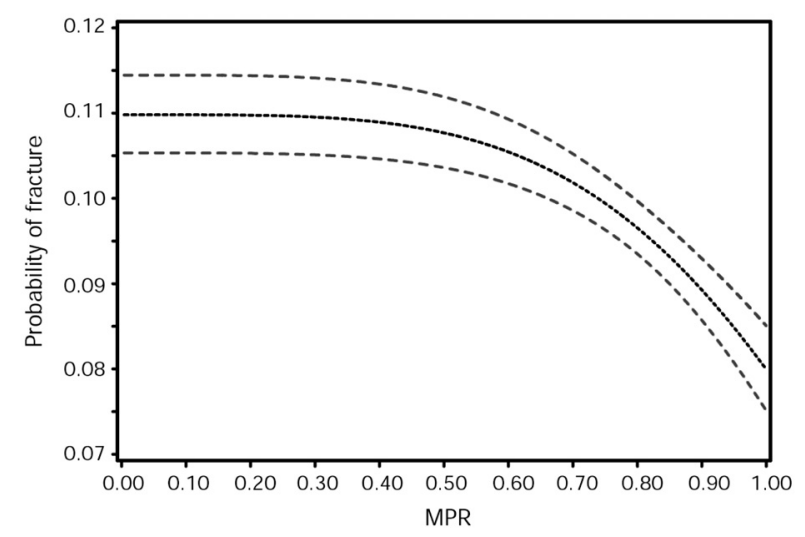

Figure 5 Probability of fracture in 24 months in the bisphosphonate-treated patients. Reproduced with permission from Siris ES, Harris ST, Rosen CJ, et al. 2006.Adherence to bisphosphonate therapy and fracture rates in osteoporotic women: relationship to vertebral and nonvertebral fractures from 2 US claims databases. Mayo Clin Proc, 81:1013-22. Copyright (c) 2006 Mayo Foundation for Medical Education and Research. All rights reserved.

Abbreviation: MPR, medication possession ratio.
0.357-0.457; $\mathrm{p}<0.0001$ ) for persistent, compared with nonpersistent, patients. Although mean MPR, as a measure of compliance, at 12 months proved significantly higher among patients receiving weekly $(\mathrm{n}=15.021)$, in contrast to daily alendronate $(n=14,136)$ (daily $=58.6 \%$; weekly $=70.5 \%$; $\mathrm{p}<0.001)$, it remained suboptimal.

All these results confirm a statistically significant association between the level of adherence with daily or weekly oral bisphosphonates and the level of fracture risk, emphasizing the need to optimize treatment adherence for obtaining maximal treatment benefit.

\section{Improvement of adherence}

In order to improve therapeutic adherence it is important to know why patients stop taking, or do not take, adequate amounts of their medication.

A survey carried out for the International Osteoporosis Foundation (IOF) by IPSOS Health in 2005 aimed to understand the reasons why women with osteoporosis do not stay on treatment. It showed that $34 \%$ of women interviewed either did not know what the benefits of their medication were or wrongly thought there were no benefits at all. As patients often have no symptoms until they suffer a fracture, they do not feel that treatment is worth taking or do not believe they have a disease that needs treatment. This means they may consider the pill burden and the inconvenience of the dosing requirements to be unnecessary. Drawbacks of treatment identified by women were predominantly related to inconvenience and side effects (IOF 2005) (see Figure 6).

Patients find the strict dosing instructions for bisphosphonates difficult to follow; fasting (overnight for at least 6 hours prior to taking the medication and 30-60 minutes after administration) and posture requirements (staying upright for 30-60 minutes after taking the medication) can be inconvenient and often not feasible in the daily routine. The strict requirements interfere not only with eating and drinking, but also with taking other medications, especially if these need to be taken with food. Despite clinical studies reporting side-effect profiles that are similar to placebo, many patients stop taking oral bisphosphonates due to AEs (McHorney et al 2007). The main complaints with oral bisphosphonates are UGIT irritation, dyspepsia, nausea, upper abdominal pain, vomiting, and gastroesophageal reflux (Reginster and Rabenda 2006).

\section{Dosing frequency}

It is acknowledged for the oral bisphosphonates that most of the above-mentioned attributes cannot be altered. However, one attribute that can be changed is the dosing frequency. 


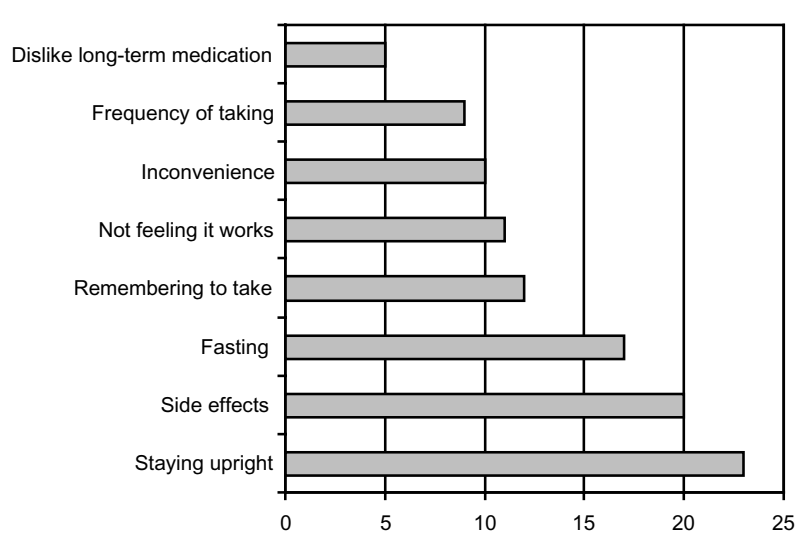

Figure 6 IOF Survey 2005: Patient drawbacks associated with oral bisphosphonates. Some patients stated more than one drawback. (Derived from IOF 2005).

Several studies have evaluated patient preferences for different dosing schedules and the impact such findings have had on therapeutic adherence. A systematic review on patient preference in the management of postmenopausal osteoporosis with (oral) bisphosphonates has recently been published in this journal (Reginster and Rabenda 2006).

Weekly regimens of oral alendronate and risedronate are both licensed and are widely accepted as being at least as effective as the daily regimens with the added convenience of only 1 tablet a week. In several studies evaluating bisphosphonate regimen preference with alendronate or risedronate, there was a strong preference for a weekly regimen vs daily dosing (Simon et al 2002; Baroutsou et al 2004; Cramer et al 2004; Kendler et al 2004; Recker et al 2004; Bartl et al 2006).

Meanwhile, improved compliance, expressed in higher MPR and/or persistence in patients treated with weekly oral bisphosphonates compared to those on daily treatment, is reported consistently in numerous studies (most recently: Recker et al 2004; Cramer et al 2005; Bartl et al 2006; Siris et al 2006; Penning-van Beest et al 2007; Rabenda et al 2007).

Cramer et al (2007) reviewed 14 reports, which described 14 databases. The overall percentage of patients persisting with therapy for 1 year ranged from $17.9 \%$ to $78.0 \%$. Compliance, assessed as mean MPR, ranged from 0.59 to 0.81 . When comparing compliance with weekly and daily bisphosphonates, the mean MPR was consistently higher for weekly vs daily therapy $(0.58-0.76$ vs $0.46-0.64$ for patients receiving weekly and daily bisphosphonate therapy, respectively). Persistence was also improved in patients receiving weekly bisphosphonates, assessed by both length of persistence (194-269 days [weekly] and 134-208 days [daily]) and percentage of persistent patients at the end of the follow-up period (35.7\%-69.7\% [weekly] and 26.1\%-55.7\% [daily]).
However, although patients using weekly bisphosphonate medication follow their prescribed dosing regimens better than those using daily therapy, overall compliance and persistence rates were suboptimal.

Ibandronate makes possible a further increase in dosing interval. It is the first and only nitrogen-containing oral bisphosphonate so far licensed for osteoporosis in a monthly regimen, and it is anticipated that this regimen may have a positive impact on adherence.

Two clinical studies using patient surveys have demonstrated a strong patient preference for a monthly vs a weekly oral bisphosphonate regimen (Emkey et al 2005; Hadji et al 2007). The BALTO (Bonviva ALendronate Trial in Osteoporosis) studies evaluated patients' preference for monthly oral ibandronate or weekly oral alendronate. BALTO I (Emkey et al 2005) in the US only and BALTO II (Hadji et al 2007) in the US and Europe comprised 2 separate studies of identical design, conducted in all together 692 bisphosphonate-naïve or bisphosphonate-lapsed women with postmenopausal osteoporosis. Patients were randomized to receive either monthly oral ibandronate for 3 months followed by weekly oral alendronate for 12 weeks, or weekly oral alendronate for 12 weeks followed by monthly oral ibandronate for 3 months. Patient preference and opinions on convenience were assessed using a subject-completed questionnaire. In both studies of those women who expressed a preference (BALTO I: 92.6\%, BALTO II: 93.1\%), the majority (BALTO I: $71.4 \%$, BALTO II: 70.6\%) preferred the monthly ibandronate regimen to the weekly alendronate regimen $(\mathrm{p}<0.0001)$. Among the most common reasons for preferring the monthly ibandronate regimen, one can identify the ease of long-term adherence and better fit to lifestyle. Patient preference for a medication may encourage therapeutic adherence, but further studies are needed to determine how well preference and convenience translate into prolonged adherence (Emkey et al 2006; Reginster and Rabenda 2006; Hadji et al 2007).

The UK PERsistence Study of Ibandronate vs alendronaTe (PERSIST) is the first trial to investigate persistence within 6 months of a monthly bisphosphonate regimen vs a weekly bisphosphonate regimen. Patients were randomized to receive either a monthly ibandronate regimen (plus a patient support program) or a weekly alendronate regimen (Cooper et al 2006). The 6-month data show that, compared with alendronate, there was a $47 \%$ relative improvement in the proportion of patients persisting with treatment in the ibandronate/patient support program group. Nevertheless, it has to be stated clearly, that the patient support program 
was available to monthly ibandronate patients only, reflecting current UK practice. It remains open, therefore, how much the data reflect on different dosing regimens and on the effect of a patient support program, respectively.

In the Risedronate Claims Study from Taylor Nelson Sofres Healthcare's online panel (Gold et al 2006), preference data were collected for weekly vs monthly bisphosphonate therapy among 617 osteoporotic women (age $\geq 50$ years) currently using bisphosphonates. In addition, the IMS longitudinal prescription database was used to evaluate adherence among patients currently taking weekly risedronate or monthly ibandronate. More patients preferred weekly over monthly therapy ( $82 \%$ vs $18 \%$ respectively, $\mathrm{p}<0.0001$ ) after receiving information about fracture efficacy differences. Adherence was significantly higher $(\mathrm{p}<0.0001)$ in patients taking weekly risedronate vs monthly ibandronate in all groups $(72.7 \pm 26.4 \%$ vs $52.8 \pm 31.5 \%$, overall sample; $51.7 \pm 31.3 \%$ vs $46.6 \pm 30.7 \%$, new to therapy; $53.0 \pm 32.2 \%$ vs $46.6 \pm 30.7 \%$, post-market). Patients preferred a weekly dosing regimen with proven vertebral and non-vertebral fracture efficacy. A monthly dosing regimen did not increase patient compliance and persistence with bisphosphonate therapy in this study.

Importantly, we do interpret the results of the rapidly growing number of studies in different treatment regimens with oral bisphosphonates. Patient compliance, persistence and adherence are complex and methods to increase adherence beyond oral dosing schedules should be further investigated (Gold et al 2006).

In an actual US study with 3274 women (age, $\geq 45$ years), who filled a prescription for an oral bisphosphonate in January or February of 2006 and were identified through a dispensing database of 3300 retail pharmacies, multivariate analyses of their standardized telephone surveys showed that those most symptomatic in terms of side effects and those with the most skeptical beliefs in drug effectiveness and drug safety had odds ratios for non-adherence of 6.78 (95\% CI 4.67-9.86), 5.70 (95\% CI 3.65-8.92), and 2.26 (95\% CI 1.49-3.42), respectively. Osteoporosis health concerns, dosing frequency convenience as well as concerns regarding medication costs were not statistically associated with non-adherence to bisphosphonate therapy (McHorney et al 2007).

\section{IV application}

A recently available alternative to oral bisphosphonate treatment is the IV application of bisphosphonates as ibandronate or zoledronate. IV ibandronate $3 \mathrm{mg}$ given quarterly is considered to be at least as effective as oral daily ibandronate
$2.5 \mathrm{mg}$ (Delmas et al 2006), which has been shown to reduce the incidence of vertebral fractures in the BONE trial. A post-hoc analysis showed that ibandronate $2.5 \mathrm{mg}$ daily reduced in addition the risk of non-vertebral fractures in a higher-risk subgroup (femoral neck BMD T score <-3.0) (Chesnut III et al 2004). The results from the ITT analysis of the HORIZON-PFT indicated that zoledronate $5 \mathrm{mg}$ once-yearly decreased significantly the risk for all relevant osteoporotic fractures: morphometric and clinical vertebral fractures, non-vertebral and hip fractures as well as all clinical fractures, respectively.

In the HORIZON-Switch trial on safety and efficacy of once-yearly IV zoledronate $5 \mathrm{mg}$ vs weekly oral alendronate $70 \mathrm{mg}$ in postmenopausal women with low BMD who had previously been treated with alendronate (McClung et al 2007), the majority (78.7\%) of patients expressed preference for once yearly infusion over weekly oral therapy. The clear preference was seen in both treatment groups of this randomized, double-blind, double-dummy study, with respect to the other parameters of convenience, such as lifestyle fit and willingness to take for an extended period of time. Answers were provided by patients under the assumption that the overall safety and effectiveness of the two treatment options were similar. Even the majority of patients who had AEs within 3 days of study drug infusion still preferred a yearly infusion (78.1\%). Given the low adherence associated with oral treatment options currently available for osteoporosis, the findings of this study are particularly promising (Omizo et al 2006).

The annual infusion ensuring "adherence" for full 12 months, despite the pharmacological specifics for zoledronate, might also account for the impressive fracture reduction potential shown for zoledronate in the HORIZON-PFT trial (Black et al 2007). 90.8\% of patients randomized to zoledronate received all three infusions, far more than reported from any other fracture outcome study with other bisphosphonates. This represents $100 \%$ compliance to the bisphosphonate therapy for 3 years - the minimum treatment duration as recommended by most guidelines worldwide - in 9 of 10 patients. This treatment option could be useful especially, but not only, in patients known for their low compliance to any long-term drug treatment:

- patients at higher ages,

- memory disorders, dementia,

- multi-medication,

- problems to stay upright or fast as required for oral bisphosphonates,

- UGIT co-morbidity or UGIT AEs with oral bisphosphonates. 
Collectively, data confirm that one aspect of patient non-adherence to oral bisphosphonates that can be changed is dosing frequency or IV application. It has been demonstrated that this preference for reduced dosing frequency influences adherence (Reginster and Rabenda 2006).

\section{Patient preferences and considerations}

Despite the data of clinical studies and surveys on patient preference, it is important that physicians consider patient preference individually when prescribing treatment for osteoporosis on case by case basis to ensure that the disease is effectively managed for the long-term benefit of the patient.

Patients with osteoporosis want an effective and welltolerated treatment. However, even with the proven efficacy and safety profiles of the bisphosphonates from clinical trials, patients still do not remain on treatment. Therefore, other strategies are needed to improve therapeutic adherence. Improved communication between physicians and their patients may be one way to help (Reginster and Rabenda 2006; Kamatari et al 2007).

The IMPACT (Improving the Measurements of Persistence on Actonel Treatment) study showed that a significant improvement in persistence was achieved whenever patients were given a positive message regarding their response to treatment, in this case verbal feedback regarding their bone turnover marker (BTM) results. Intervention based on a good BTM response was associated with a significant improvement in persistence (HR 0.71; 95\% CI 0.53-0.95). Persistence was unchanged or lower when reinforcement was based on a stable or poor BTM response, respectively (Delmas et al 2007).

According to Reginster and Rabenda in their 2006 review on patient preference, it has also been indicated in other chronic conditions that involving patients in treatment decisions and matching the decisions with the preferences improves patient satisfaction, adherence, perception of health and, ultimately, the outcomes (Lopes et al 2001; Janz et al 2004; Jahng et al 2005; Lin et al 2005).

In the IOF Adherence Gap Report (2005), nine out of ten patients surveyed acknowledged that osteoporosis is a serious disease - a finding corresponding to the response provided by the same proportion of physicians $(88 \%)$. Despite the apparent agreement on this point, there still seem to be gaps in understanding between patients and physicians. Physicians are aware that a large proportion of their patients discontinue treatment; however, 71\% reported that they did not know why patients stopped therapy, $86 \%$ were unsure about how best to motivate patients to continue their medication, and
$41 \%$ had attempted to motivate their patients by stressing the possibility of risks and complications. With respect to the last, interviews with the affected women in this survey reveal that negative motivators may not necessarily be the best approach, as what motivated women in fact most was to know that they were doing something to help themselves. This would seem to point towards the need to positively encourage patients by highlighting the benefits of treatment rather than making them afraid of the negative consequences of non-adherence. Less frequent oral dosing emerged as another popular option as a means of improving adherence to treatment, because it had the potential to reduce both, the inconvenience surrounding current dosing regimens and the frequency of side effects (IOF 2005). It might be assumed that similar findings could be attributed to the once-yearly or quarterly IV application instead of monthly or weekly oral regimens since IV bisphosphonates were not yet available at the time of the survey.

\section{Conclusions}

Nitrogen-containing bisphosphonates are potent inhibitors of osteoclastic bone resorption and share, as a class, similar pharmacological properties. They have been proven in numerous outcome trials in postmenopausal osteoporosis to significantly reduce the incidence of vertebral fractures (alendronate, ibandronate, risedronate, zoledronate). Risk reduction for non-vertebral and hip fractures has been shown for risedronate and zoledronate in ITT populations, and for alendronate in sub-group analyses. Also ibandronate has shown non-vertebral fracture risk reduction in a post-hoc sub-group analysis. With proven efficacy and an overall beneficial safety profile, nitrogen-containing bisphosphonates are considered a treatment of first choice in postmenopausal osteoporosis. Treatment effects in an individual patient and cost-effectiveness in public health perspective are vitally dependent on long-term patient adherence, on compliance and persistence. As compliance and persistence with daily oral bisphosphonates are suboptimal in many patients and fracture incidence is increased in these patients, there is a need to improve overall adherence to bisphosphonate treatment to achieve maximum treatment effects. One option is to extend dosing intervals to weekly (alendronate, risedronate) or monthly (ibandronate) oral regimens. Another alternative is IV instead of oral application (ibandronate, zoledronate). Less frequent oral regimens are generally preferred by majority of patients. First studies have shown that the acceptance could be further improved by IV bisphosphonates with their benefit of only quarterly or even once-yearly application. 
Physicians should make use of the ever increasing number of treatment options and alternatives with different nitrogencontaining bisphosphonates. Their treatment decisions should be based on anti-fracture efficacy data first. However, to ensure best possible patient adherence, they should take into consideration from the very beginning individual patient conditions affecting compliance and persistence (such as age, multimedication, gastrointestinal co-morbidity) as well as patient preferences (such as lifestyle, convenience). It is important that physicians discuss all options with their patients before a treatment choice is made and monitor patient adherence, particularly in oral bisphosphonates. IV bisphosphonates are, in general, a new and promising alternative to oral regimens.

To achieve maximum treatment benefits for patients with osteoporosis in a long-term perspective, alternative treatment options offered by the different nitrogen-containing bisphosphonates with different applications and dosing intervals should be used consciously and, consequently, in close co-operation between physicians and patients. Chances and choice have never been better.

\section{Acknowledgment}

The authors would like to thank Malgorzata Sylwia Wolinska, University of Geneva, for her editorial assistance in reviewing the paper.

\section{Disclosures}

Neither author has any conflicts of interest to declare.

\section{References}

Adachi J, Lynch N, Middelhoven H, et al. 2007. The association between compliance and persistence with bisphosphonate therapy and fracture risk: a review. BMC Musculoskelet Disord, 8:97.

Allen MR, Burr DB. 2008. Changes in vertebral strength-density and energy absorption-density relationships following bisphosphonate treatment in beagle dogs. Osteoporos Int, 19:95-9.

Allen MR, Iwata K, Phipps R, et al. 2005. Risedronate and alendronate similarly suppress remodeling and increase microdamage in beagles after 1 year of treatment at clinical doses. 27th Annual Meeting of the American Society for Bone and Mineral Research 2005; Nashville, Tennessee, USA; J Bone Miner Res, 20(Suppl 1):S22.

Badamgarav E, Fitzpatrick LA. 2006. A new look at osteoporosis outcomes: the influence of treatment, compliance, persistence, and adherence. Mayo Clin Proc, 81:1009-12.

Baroutsou B, Babiolakis D, Stamatiadou A, et al. 2004. Patient compliance and preference of alendronate once weekly administration in comparison with daily regimens for osteoporotic postmenopausal women. Ann Rheum Dis, 63(Suppl 1):455.

Bartl R, Goette S, Hadji P, et al. 2006. Persistence and compliance with daily- and weekly-administered bisphosphonates in German women with osteoporosis. Ann Rheum Dis, 64(Suppl 3):364.

Bartl R, Götte S, Hadji P, Hammerschmidt T. 2006. Adherence with daily and weekly administration of oral bisphosphonates for osteoporosis treatment [Article in German]. Dtsch Med Wochenschr, 131:1257-62.
Benner JS, Glynn RJ, Mogun H, et al. 2002. Long term persistence in use of statin therapy in elderly patients. JAMA, 288:455-61.

Black DM, Boonen S, Cauley J, et al. 2006. Effect of once-yearly infusion of zoledronic acid $5 \mathrm{mg}$ on spine and hip fracture reduction in postmenopausal women with osteoporosis: The HORIZON Pivotal Fracture Trial. The American College of Rheumatology Annual Scientific Meeting 2006, November 10-15; Washington DC, USA. Abstract 665.

Black DM, Cummings SR, Karpf DB, et al. 1996. Randomised trial of effect of alendronate on risk of fracture in women with existing vertebral fractures. Fracture Intervention Trial Research Group. Lancet, 348:1535-41.

Black DM, Delmas PD, Eastell R, et al. 2007. Once-yearly zoledronic acid for treatment of postmenopausal osteoporosis. $N$ Engl J Med, 356(18):1809-22.

Black DM, Rosen CJ. 2007. Is risedronate or alendronate more effective at preventing nonvertebral fractures in women with osteoporosis? Nat Clin Pract Rheumatol, 3:378-9.

Black DM, Schwartz AV, Ensrud KE, et al. 2006. Effects of continuing or stopping alendronate after 5 years of treatment: the Fracture Intervention Trial Long-term Extension (FLEX): a randomized trial. JAMA, 296:2927-38.

Bock O, Boerst H, Thomasius FE, et al. 2007. Common musculoskeletal adverse effects of oral treatment with once weekly alendronate and risedronate in patients with osteoporosis and ways for their prevention. J Musculoskelet Neuronal Interact, 7(2):144-8.

Boivin GY, Chavassieux PM, Santora AC, et al. 2000. Alendronate increases bone strength by increasing the mean degree of mineralization of bone tissue in osteoporotic women. Bone, 27:687-94.

Boonen S, Laan RF, Barton IP, et al. 2005. Effect of osteoporosis treatments on risk of non-vertebral fractures: review and meta-analysis of intention-to-treat studies. Osteoporos Int, 16:1291-8.

Bounameaux HM, Schifferli J, Montani JP, et al. 1983. Renal failure associated with intravenous diphosphonates. Lancet, 1(8322):471.

Brankin E, Walker M, Lynch N, et al. 2006. The impact of dosing frequency on compliance and persistence with bisphosphonates among postmenopausal women in the UK: evidence from three databases. Curr Med Res Opin, 22:1249-56.

Brazier JE, Green C, Kanis JA; Committee Of Scientific Advisors International Osteoporosis Foundation. 2002. A systematic review of health state utility values for osteoporosis-related conditions. Osteoporos Int, 13:768-76.

Briesacher BA, Andrade SE, Yood RA, et al. 2007. Consequences of poor compliance with bisphosphonates. Bone, 41:882-7.

Brown JP, Kendler DL, McClung MR, et al. 2002. The efficacy and tolerability of risedronate once a week for the treatment of postmenopausal osteoporosis. Calcif Tissue Int, 71:103-11.

Browner WS, Pressman AR, Nevitt MC, et al. for the Study of Osteoporotic Fractures Research Group. 1996. Mortality following fractures in older women. Arch Intern Med, 156:1521-5.

Caro JJ, Ishak KJ, Huybrechts KF, et al. 2004. The impact of compliance with osteoporosis therapy on fracture rates in actual practice. Osteoporos Int, 15:1003-8.

Cauley JA, Thompson DE, Ensrud KC, et al. 2000. Risk of mortality following clinical fractures. Osteoporos Int, 11:556-61.

Center JR, Nguyen TV, Schneider D, et al. 1999. Mortality after all major types of osteoporotic fracture in men and women: an observational study. Lancet, 353:878-82.

Chang JT, Green L, Beitz J. 2003. Renal failure with the use of zoledronic acid. $N$ Engl J Med, 349:1676-9.

Chapurlat RD, Delmas PD. 2006. Drug insight: Bisphosphonates for postmenopausal osteoporosis. Nat Clin Pract Endocrinol Metab, 2:211-9.

Chesnut III CH, Skag A, Christiansen C, et al. 2004. Effects of oral ibandronate administered daily or intermittently on fracture risk in postmenopausal osteoporosis. J Bone Miner Res, 19:1241-9.

Christensen DB, Williams B, Goldberg HI, et al. 1997. Assessing compliance to antihypertensive medication using computer-based pharmacy records. Med Car, 35:1164-70. 
Compston J. 2007. Treatments for osteoporosis - looking beyond the HORIZON (editorial). N Engl J Med, 356:1878-80.

Cooper C. 1999. Epidemiology of osteoporosis. Osteoporosis Int, 9(Suppl 2):S2-8.

Cooper C, Atkinson EJ, Jacobsen SJ, et al. 1993. Population-based study of survival after osteoporotic fractures. AMJ Epidemiol, 137:1001-5.

Cooper A, Drake J, Brankin E, the PERSIST Investigators. 2006. Treatment persistence with once monthly ibandronate and patient support vs once-weekly alendronate: results from the PERSIST study. Int $J$ Clin Pract, 60:896-905.

[CPMP] Committee for Proprietary Medicinal Products. 2001. Note for guidance on postmenopausal osteoporosis in women. Committee for Proprietary Medicinal Products, London.

Cramer JA, Amonkar M, Hebborn A, et al. 2004. Assessing the relationship between bisphosphonate dosing regimen and treatment adherence among post-menopausal osteoporotic women. Arthritis Rheum, 50(Suppl):S294.

Cramer JA, Amonkar MM, Hebborn A, et al. 2005. Compliance and persistence with bisphosphonate dosing regimens among women with postmenopausal osteoporosis. Curr Med Res Opin, 21:1453-60.

Cramer JA, Gold DT, Silverman SL, et al. 2007. A systematic review of persistence and compliance with bisphosphonates for osteoporosis. Osteoporos Int, 18:1023-31.

Cramer J, Lynch NO, Gaudin A-F, et al. 2006. The impact of dosing frequency on compliance and persistence with bisphosphonate therapy among post-menopausal women: a comparison of studies in USA, UK and France. Clin Therapeut, 28:1686-94.

Cranney A, Wells G, Willan A, et al. 2002. II. Meta-analysis of alendronate for the treatment of postmenopausal women. Endocr Rev, 23:508-16.

Cummings SR, Black DM, Thompson DE, et al. 1998. Effect of alendronate on risk of fracture in women with low bone density but without vertebral fractures: results from the Fracture Intervention Trial. JAMA, 280:2077-82.

Cummings SR, Schwartz AV, Black DM. 2007. Alendronate and atrial fibrillation. $N$ Engl J Med, 356:1895-6.

Delmas PD, Adami S, Strugala C, et al. 2006. Intravenous ibandronate injections in postmenopausal women with osteoporosis: one-year results from the dosing intravenous administration study. Arthritis Rheum, 54:1838-46.

Delmas PD, Vrijens B, Eastell R, et al. 2007. Effect of monitoring bone turnover markers on persistence with risedronate treatment of postmenopausal osteoporosis. J Clin Endocrinol Metab, 92:1296-304.

Dunford JE, Thompson K, Coxon FP, et al. 2001. Structure-activity relationships for inhibition of farnesyl diphosphate synthase in vitro and inhibition of bone resorption in vivo by nitrogen-containing bisphosphonates. J Pharmacol Exp Ther, 296:235-42.

[EMEA] European Agency for the Evaluation of Medicinal Products. 1998. ICH Topic E9. Note for guidance on statistical principles for clinical trials. The European Agency for the Evaluation of Medicinal Products.

Emkey R, Koltun W, Beusterien K, et al. 2005. Patient preference for once-monthly ibandronate vs once-weekly alendronate in a randomized, open-label, cross-over trial: the Bonviva Alendronate Trial in Osteoporosis (BALTO). Curr Med Res Opin, 21:1895-903.

Ensrud KE, Thompson DE, Cauley JE, et al. 2000. Prevalent vertebral deformities predict mortality and hospitalisation in older women with low bone mass. J Amer Geriatr Soc, 48:241-9.

[FDA] US Food and Drug Administration. 1994. Guidelines for preclinical and clinical evaluation of agents used in the prevention or treatment of postmenopausal osteoporosis. US Food and Drug Administration.

Felsenberg D, Hoffmeister B, Amling M, et al. 2006. Onkologie: Kiefernekrosen nach hoch dosierter Bisphosphonattherapie [Article in German]. Dtsch Arztebl, 103: A-3078-80.

Fleisch HA (ed). 1997. Bisphosphonates in Bone Disease. From the Laboratory to the Patient. 3rd edition, New York: Parthenon Publishing.

Forsén L, Søgaard AJ, Meyer HE, et al. 1999. Survival after hip fracture: short- and long-term excess mortality according to age and gender. Osteoporos Int, 10:73-8.
Goettsch WG, Penning F, Erkens JE, et al. 2005. Persistent bisphosphonate usage reduces the risk of hospitalizations for osteoporotic fractures. J Bone Miner Res, 20(Suppl 1):S278.

Gold DT, Safi W, Trinh H. 2006. Patient preference and adherence: comparative US studies between two bisphosphonates, weekly risedronate and monthly ibandronate. Curr Med Res Opin, 22:2383-91.

Gullberg B, Johnell O, Kanis JA. 1997. Worldwide projections for hip fracture. Osteoporosis Int, 7:407-13.

Hadji P, Minne H, Pfeifer M, et al. 2007. Treatment preference for monthly oral ibandronate and weekly oral alendronate in women with postmenopausal osteoporosis: A randomized, crossover study (BALTO II). Joint Bone Spine, 2007 Oct 22; [Epub ahead of print].

Harris ST, Siris E, Abbott T, et al. 2005. Reduced osteoporotic fracture risk in patients adherent to bisphosphonate therapy. 87th Annual Meeting of The Endocrine Society, 4-7 June 2005, Programme and Abstracts: 3-382.

Harris ST, Watts NB, Genant HK, et al. 1999. Effects of risedronate treatment on vertebral and nonvertebral fractures in women with postmenopausal osteoporosis: a randomized controlled trial. Vertebral Efficacy With Risedronate Therapy (VERT) Study Group. JAMA, 282:1344-52.

Hasserius R, Karlsson MK, Nilsson BE, et al. 2003. Prevalent vertebral deformities predict increased mortality and increased fracture rate in both men and women: a 10 year population-based study of 598 individuals from the Swedish cohort in the European Vertebral Osteoporosis Study. Osteoporos Int, 14:61-8.

[IOF] International Osteoporosis Foundation. 2005. IOF adherence gap report [online]. Accessed 7 January 2008. URL: http://www.osteofound. org/publications/pdf/adherence_gap_report.pdf.

Ismail AA, O'Neill TW, Cooper C, et al. on behalf of the EPOS Study Group. 1998. Mortality associated with vertebral deformity in men and women: results from the European Prospective Osteoporosis Study (EPOS). Osteoporos Int, 8:291-7.

Jacobsen SJ, Goldberg J, Miles TP, et al. 1992. Race and sex differences in mortality following fracture in hip. Am J Public Health, 82:1147-50.

Jahng KH, Martin LR, Golin CE, et al. 2005. Preferences for medical collaboration: patient-physician congruence and patient outcomes. Patient Educ Couns, 57:308-14.

Janz NK, Wren PA, Copeland LA, et al. 2004. Patient-physician concordance: preferences, perceptions, and factors influencing the breast cancer surgical decision. J Clin Oncol, 22:3091-8.

Johnell O. 1997. The socioeconomic burden of fractures: today and in the 21st century. Am J Med, 103:S20-S25.

Johnell O, Haglund B. 1999. Co-morbidity and mortality in hip fracture patients: a population-based study. J Bone Miner Res, 14(Suppl 1): S160.

Johnell O, Kanis JA. 2004. An estimate of the worldwide prevalence, mortality and disability associated with hip fracture. Osteoporos Int, 15:897-902.

Johnell O, Kanis JA, Odén A, et al. 2004. Mortality after osteoporotic fractures. Osteoporos Int, 15:38-42.

Johnell O, Kanis J. 2005. Epidemiology of osteoporotic fractures. Osteoporos Int, 16 (Supp1 2):S3-7.

Johnell O, Kanis JA. 2006. An estimate of the worldwide prevalence and disability associated with osteoporotic fractures. Osteoporos Int, 17:1726-33.

Kado DM, Browner WS, Palermo L, et al. 1999. Vertebral fractures and mortality in older women. The study of osteoporotic fractures. Arch Intern Med, 159:1215-20.

Kamatari M, Koto S, Ozawa N, et al. 2007. Factors affecting long-term compliance of osteoporotic patients with bisphosphonate treatment and QOL assessment in actual practice: alendronate and risedronate. J Bone Miner Metab, 25:302-9.

Kanis JA. 2002. Diagnosis of osteoporosis and assessment of fracture risk. Lancet, 359:1929-36.

Kanis JA, Delmas PD, Burckhardt P, et al. 1997. Guidelines for diagnosis and management of osteoporosis. The European Foundation for Osteoporosis and Bone Disease. Osteoporosis Int, 7:390-406.

Kanis JA, Pitt FA. 1992. Epidemiology of osteoporosis. Bone, 13:S7-S15. 
Kavanagh KL, Dunford JE, Bunkoczi G, et al. 2006a. The crystal structure of human geranylgeranyl pyrophosphate synthase reveals a novel hexameric arrangement and inhibitory product binding. $J$ Biol Chem, 281:22004-12.

Kavanagh KL, Guo K, Dunford JE, et al. 2006b. The molecular mechanism of nitrogen-containing bisphosphonates as antiosteoporosis drugs. Proc Natl Acad Sci USA, 103:7829-34.

Kendler D, Kung AW, Fuleihan Gel H, et al. 2004. Patients with osteoporosis prefer once weekly to once daily dosing with alendronate. Maturitas, 48:243-51.

Khosla S, Burr D, Cauley J, et al. 2007. Bisphosphonate-associated osteonecrosis of the jaw: report of a task force of the American Society for Bone and Mineral Research. J Bone Miner Res, 22:1479-91.

Komatsubara S, Mori S, Mashiba T, et al. 2003. Long-term treatment of incadronate disodium accumulates microdamage but improves the trabecular bone microarchitecture in dog vertebra. J Bone Miner Res, 18:512-20.

Lau EMC, YH Chan, M Chan, et al. 2000. Vertebral deformity in Chinese men: prevalence, risk factors, bone mineral density and body composition measurements. Calcif Tissue Int, 66:47-52

Lewiecki EM, Miller PD. 2007. Renal safety of intravenous bisphosphonates in the treatment of osteoporosis. Expert Opin Drug Saf, 6:663-72.

Lin JH, Chen IW, Deluna FA, Hichens M. 1992. Renal handling of alendronate in rats. An uncharacterized renal transport system. Drug Metab Dispos, 20:608-13.

Lin JH, Chen IW, Deluna FA, Hichens M. 1993. Role of calcium in plasma protein binding and renal handling of alendronate in hypo- and hypercalcemic rats. J Pharmacol Exp Ther, 267:670-5.

Lin P, Campbell DG, Chaney EE, et al. 2005. The influence of patient preference on depression treatment in primary care. Ann Behav Med, 30:164-73.

Lombas C, Hakim C, Zanchetta JR. 2001. Compliance with alendronate treatment in an osteoporosis clinic. J Bone Miner Res, 15:S529.

Lopes P, Rozenberg S, de Graaf J, et al. 2001. Aerodiol vs the transdermal route: perspectives for patient preference. Maturitas, 38(Suppl 1):S31-9.

Luckman SP, Hughes DE, Coxon FP, et al. 1998. Nitrogen-containing bisphosphonates inhibit the mevalonate pathway and prevent post-translational prenylation of GTP-binding proteins, including Ras. J Bone Miner Res, 13:581-9.

Lyles KW, Colón-Emeric CS, Magaziner JS, et al. 2007. Zoledronic acid and clinical fractures and mortality after hip fracture. $N$ Engl J Med, 357:1799-809.

Magaziner J, Simonsick EM, Kashner M, et al. 1989. Survival experience of aged hip fracture patients. Am J Public Health, 73:274-8.

Mashiba T, Mori S, Burr DB, et al. 2005. The effects of suppressed bone remodeling by bisphosphonates on microdamage accumulation and degree of mineralization in the cortical bone of dog rib. J Bone Miner Metab, 23 (Suppl):S36-42.

McCloskey E. 2006. Health-related quality of life in osteoporosis. Medicographia, 28:33-9.

McClung MR, Geusens P, Miller PD, et al. 2001. Effect of risedronate on the risk of hip fracture in elderly women. Hip Intervention Program Study Group. N Engl J Med, 344:333-40.

McClung M, Recker R, Miller P, et al. 2007. Intravenous zoledronic acid 5 $\mathrm{mg}$ in the treatment of postmenopausal women with low bone density previously treated with alendronate. Bone, 41:122-8.

McCombs JS, Thiebaud P, McLaughlin-Miley C, Shi J. 2004. Compliance with drug therapies for the treatment and prevention of osteoporosis. Maturitas, 48:271-87.

McHorney CA, Schousboe JT, Cline RR, Weiss TW. 2007. The impact of osteoporosis medication beliefs and side-effect experiences on nonadherence to oral bisphosphonates. Curr Med Res Opin, 23:3137-52.

Mellström DD, Sörensen OH, Goemaere S, et al. 2004. Seven years of treatment with risedronate in women with postmenopausal osteoporosis. Calcif Tissue Int, 75:462-8.

Melton III LJ, Chrischilles EA, Cooper C, et al. 1992. Perspective: How many women have osteoporosis? J Bone Miner Res, 7:1005-10.
Melton LJ III, Therneau TM, Larson DR. 1998. Long-term trends in hip fracture prevalence: the influence of hip fracture incidence and survival. Osteoporos Int, 8:68-74.

Miller NH. 1997. Compliance with treatment regimens in chronic asymptomatic diseases. Am J Med, 102:43-9.

Miller PD. 2008. Non-vertebral fracture risk reduction with oral bisphosphonates: challenges with interpreting clinical trial data. Curr Med Res Opin, 24:107-19.

Nancollas GH, Tang R, Phipps RJ, et al. 2006. Novel insights into actions of bisphosphonates on bone: differences in interactions with hydroxyapatite. Bone, 38:617-27.

Nevitt MC, Thompson DE, Black DM, et al. 2000. Effect of alendronate on limited-activity days and bed-disability days caused by back pain in postmenopausal women with existing vertebral fractures. Fracture Intervention Trial Research Group. Arch Intern Med, 160:77-85.

Nguyen ND, Ahlborg HG, Center JR, et al. 2007. Residual lifetime risk of fractures in women and men. J Bone Miner Res, 22:781-8.

[NIH] National Institutes of Health. 2001. NIH Consensus Development Panel on Osteoporosis Prevention, Diagnosis, and Therapy. Osteoporosis prevention, diagnosis, and therapy. JAMA, 285:785-95.

Omizo M, McClung M, Minkoff J, et al. 2006. A Single Annual Infusion Is Preferred to Oral Weekly Treatment in Postmenopausal Women with Low Bone Mineral Density Previously Treated with Alendronate. 28th Annual Meeting of the American Society for Bone and Mineral Research 2006, Philadelphia, Pennsylvania, USA; J Bone Miner Res, 21 (Suppl 1):SU329.

Papaioannou A, Ioannidis G, Adachi JD, et al. 2003. Adherence to bisphosphonates and hormone replacement therapy in a tertiary care setting of patients in the CANDOO database. Osteoporos Int, 14:808-13.

Papapoulos SE. 2001. Bisphosphonates in the management of postmenopausal osteoporosis. In: Marcus R et al. (ed). Osteoporosis. 2nd edition. San Diego: Academic Press. p 631-50.

Payer J, Killinger Z, Sulková I, Celec P. 2007. Therapeutic adherence to bisphosphonates. Biomed Pharmacother, 61:191-3.

Pedersen-Bjergaard U, Myhre J. 1991. Severe hypocalcaemia after treatment with diphosphonate and aminoglycoside. BMJ, 302:295.

Penning-van Beest FJ, Erkens JA, Olson M, Herings RM. 2007. Loss of treatment benefit due to low compliance with bisphosphonate therapy. Osteoporos Int. 2007 Sep 14; [Epub ahead of print].

Randell A, Sambrook PN, Nguyen TV, et al. 1995. Direct clinical and welfare costs of osteoporotic fractures in elderly men and women. Osteoporosis Int, 5:427-32.

Recker R, Ensrud K, Diem S, et al. 2004. Normal Bone Histomorphometry and 3D Microarchitecture After 10 Years Alendronate Treatment of Postmenopausal Women. 26th Annual Meeting of the American Society for Bone and Mineral Research 2004, Seattle, Washington, USA; J Bone Miner Res, 19(Suppl 1):S45.

Recker RR, Gallagher R, Amonkar AA, et al. 2004. Medication persistence is better with weekly bisphosphonates, but it remains suboptimal. J Bone Miner Res, 19(Suppl 1):S172.

Reginster JY, Abadie E, Delmas P, et al. 2006. Recommendations for an update of the current (2001) regulatory requirements for registration of drugs to be used in the treatment of osteoporosis in postmenopausal women and in men. Osteoporos Int, 17:1-7.

Reginster JY, Adami S, Lakatos P, et al. 2006. Efficacy and tolerability of once-monthly oral ibandronate in postmenopausal osteoporosis: 2 year results from the MOBILE study. Ann Rheum Dis, 65:654-61.

Reginster JY. Burlet N. 2006. Osteoporosis: A still increasing prevalence. Bone, 38:S4-9.

Reginster J, Minne HW, Sorensen OH, et al. 2000. Randomized trial of the effects of risedronate on vertebral fractures in women with established postmenopausal osteoporosis. Vertebral Efficacy with Risedronate Therapy (VERT) Study Group. Osteoporos Int, 11:83-91

Reginster JY, Rabenda V. 2006. Patient preference in the management of postmenopausal osteoporosis with bisphosphonates. Clin Interv Aging, 1:415-23. 
Reid DM, Hosking D, Kendler D, et al. 2006. Alendronic acid produces greater effects than risedronic acid on bone density and turnover in postmenopausal women with osteoporosis : results of FACTS -international. Clin Drug Investig, 26:63-74.

Ridley AJ, Hall A. 1992. The small GTP-binding protein rho regulates the assembly of focal adhesions and actin stress fibers in response to growth factors. Cell, 70:389-99.

Riis BJ, Ise J, von Stein T, et al. 2001. Ibandronate: a comparison of oral daily dosing vs intermittent dosing in postmenopausal osteoporosis. $J$ Bone Miner Res, 16:1871-8.

Ringe JD, Body JJ. 2007. A review of bone pain relief with ibandronate and other bisphosphonates in disorders of increased bone turnover. Clin Exp Rheumatol, 25:766-74.

Rizzoli R, Greenspan SL, Bone G 3rd, et al. 2002. Two-year results of once-weekly administration of alendronate $70 \mathrm{mg}$ for the treatment of postmenopausal osteoporosis. J Bone Miner Res, 17:1988-96.

Rosen CJ, Hochberg MC, Bonnick SL, et al. 2005. Treatment with onceweekly alendronate $70 \mathrm{mg}$ compared with once-weekly risedronate $35 \mathrm{mg}$ in women with postmenopausal osteoporosis: a randomized double-blind study. J Bone Miner Res, 20:141-51.

Russell RGG. 2007. Determinants of structure - function relationships among bisphosphonates. Bone, 40(Suppl 2):S21-25.

Sambrook P, Cooper C. 2006. Osteoporosis. Lancet, 367:2010-18.

Schwartz AV, Kelsey JL, Maggi S, et al. 1999. International variation in the incidence of hip fractures: cross-national project on osteoporosis for the World Health Organization programme for research on ageing. Osteoporos Int, 9:242-53.

Sebaldt RJ, Shane L, Pham B, et al. 2004. Longer-term effectiveness outcomes of non-compliance and non-persistence with daily-regimen bisphosphonate therapy in patients with osteoporosis treated in tertiary specialist care. Osteoporos Int, 15(Suppl 1): S107.

Segal E, Tamir A, Ish-Shalom S. 2003. Compliance of osteoporotic patients withdifferent treatment regimens. Isr Med Assoc J, 5: 859-62.
Sernbo I, Johnell O. 1993. Consequences of a hip fracture: a prospective study over 1 year. Osteoporos Int, 3:148-53.

Silverman SL, Watts NB, Delmas PD, et al. 2007. Effectiveness of bisphosphonates on nonvertebral and hip fractures in the first year of therapy: the risedronate and alendronate (REAL) cohort study. Osteoporos Int, 18:25-34.

Simon JA, Lewiecki EM, Smith ME, et al. 2002. Patient preference for onceweekly alendronate $70 \mathrm{mg}$ vs once-daily alendronate $10 \mathrm{mg}$ : a multicenter, randomized, open-label, cross-over study. Clin Ther, 24:1871-86.

Siris ES, Harris ST, Rosen CJ, et al. 2006. Adherence to bisphosphonate therapy and fracture rates in osteoporotic women: relationship to vertebral and nonvertebral fractures from 2 US claims databases. Mayo Clin Proc, 81:1013-22.

Strampel W, Emkey R, Civitelli R. 2007. Safety considerations with bisphosphonates for the treatment of osteoporosis. Drug Saf, 30:755-63.

Tankó LB, Mouritzen U, Lehmann HJ, et al. 2003. Oral ibandronate: changes in markers of bone turnover during adequately dosed continuous and weekly therapy and during different suboptimally dosed treatment regimens. Bone, 32:687-93.

Todd C, Freeman C, Camilleri-Ferrante C, et al. 1995. Differences in mortality after fracture of the hip. BMJ, 310:904-8.

Weiss NS, Liff JM, Ure CL, et al. 1983. Mortality in women following hip fracture. J Chron Dis, 12:879-82.

Weycker D, Macarios D, Edelsberg J, Oster G. 2006. Compliance with drug therapy for postmenopausal osteoporosis. Osteoporosis Int, $17: 1645-52$.

[WHO] World Health Organization. 2003a. Prevention and management of osteoporosis. Report of a WHO scientific group. World Health Organ Tech Rep Ser, 921:1-164.

[WHO] World Health Organization. 2003b. Adherence to long-term therapies: evidence for action. World Health Organization, pp1-211.

Yood RA, Emani S, Reed JI, et al. 2003. Compliance with pharmacologic therapy for osteoporosis. Osteoporos Int, 14:965-68. 
